\title{
The Homicide of United States Marine Corps Colonel, James E. Sabow: A Forensic Analysis Submitted to the United States Congress
}

\section{Bryan R Burnett ${ }^{*}$}

Meixa Tech, Cardiff, USA

\begin{abstract}
The official position of the United States Government is Marine Corps Colonel James E. Sabow committed suicide. He allegedly died by an intraoral shotgun discharge in the backyard of his quarters on the El Toro Marine Corps Air Station, Orange County, California, USA in 1991. However, questions have persisted since the Colonel's death whether he died by homicide. The two scenarios on the manner of death, suicide and homicide, were evaluated as to the gunshot residue (GSR) and back spatter residue (BSR) on the Colonel's clothing, the bloodstains on and off the body and the position of the body at the death scene. The shotgun, when test fired, was shown to leak GSR from its breech and trigger housing. Samples from the Colonel's clothing were analysed by scanning electron microscopy/energy dispersive X-ray analysis show there are no concentrations of GSR or BSR on the clothing that should be present if the Colonel committed suicide. Bloodstains on and away from the body and the position of the body do not support the suicide scenario, The Colonel's body was staged to appear he committed suicide. There is no evidence of suicide. The Colonel's death was a homicide.
\end{abstract}

Keywords: Forensic science; Crime scene reconstruction; Gunshot residue; Back spatter residue; Homicide; Shotgun; Staged suicide

\section{Introduction}

On January 22, 1991, Marine Corps Colonel James E. Sabow was found dead in the backyard of his quarters at the United States Marine Corps Air Station, El Toro, California, USA. He was on his right side dressed in a white terrycloth bathrobe, white undershirt, light blue pajama bottom, white socks and black slippers (Figure 1). The death certificate issued the next day by the Orange County Coroner, California, USA, concluded the Colonel had died by suicide [1]. The death was alleged to be by an intraoral shotgun discharge. The close proximity of the victim's shotgun (Ithaca 12 gauge double barrel shotgun) to his body (Figure 1) as well as a patio chair on top of him supported a suicide scenario at first impression. However, bloodstains away from the body, the autopsy report and photographs and the death scene photographs indicate homicide. This article will examine the evidence and reconstruct the manner death of the Colonel.

In 2003 United States Congressman Duncan Hunter, Chairman of the Armed Services Committee, was apprised of the controversy regarding the manner of the Colonel's death. In response, Congressman Hunter amended the United States Defense Authorization Bill for 2004 to include instruction to the Department of Defense for a reinvestigation of the death. The Department of Defense chose Dr. Jon Nordby to conduct the mandated investigation which resulted in a report [2] submitted to the Department of Defense and the Congress. That report concluded the Colonel committed suicide.

The present article, an alternative forensic report to Nordby's report, was financed in part by the Sabow family and submitted in 2006 to Congressman Hunter who left office in 2007 without comment on the conclusions of this report. The Congressman has refused any comment since on the manner of the Colonel's death despite being presented with irrefutable evidence of homicide.

In 2012 one of the autopsy photographs released by the United States Department of Defense was discovered to be fraudulent [3]. This fraudulent photograph was generated from the Department of Defense for use in a civil case in United States Federal Court in 1994.
A second version of the fraudulent photograph [3] was used by Nordby in his report to the Department of Defense and the US Congress [2] to support his conclusion the Colonel committed suicide. Nordby generate two reports $[2,4]$ in this case. Both were seriously flawed in most other aspects of his analysis.

\section{The Suicide and Homicide Scenarios}

\section{Suicide}

The Colonel committed suicide with his Ithaca 12 gauge double barrel shotgun by sitting in a chair placing the shotgun in his mouth. The shotgun muzzle was held at his mouth with his left hand and he pushed the trigger with a finger or the thumb of his right hand (Figure $2 \mathrm{~A}$ ). The position of the body (Figures 1 and 3 ) suggests consistent with this scenario, the shotgun was held outside his right leg and after the shot, he somehow fell backward from the chair and onto his right side causing the patio chair to upset and land on top of him. This is the theory promulgated by Nordby $[2,4]$. The death scene is illustrated in Figure 3 which also shows the suicide interpretation of the Colonel's death.

\section{Homicide}

The Colonel received a blow to the back of his head, which rendered a fatal injury. While the he was lying on the ground, the assailant inserted the victim's 12 gauge double barreled shotgun into his mouth and fired the left barrel. This part of the scenario is reenacted in Figure 2B. The shotgun was

*Corresponding author: Bryan R Burnett, Meixa Tech, P.O. Box 844, Cardiff, CA-92007, USA, Tel: (760) 634-5939; Email: brburnett@meixatech.com

Received November 22, 2016; Accepted January 05, 2017; Published January 09,2017

Citation: Burnett BR (2017) The Homicide of United States Marine Corps Colonel, James E. Sabow: A Forensic Analysis Submitted to the United States Congress. J Forensic Res 7: 362. doi: 10.4172/2157-7145.1000362

Copyright: @ 2017 Burnett BR. This is an open-access article distributed under the terms of the Creative Commons Attribution License, which permits unrestricted use, distribution, and reproduction in any medium, provided the original author and source are credited. 
Citation: Burnett BR (2017) The Homicide of United States Marine Corps Colonel, James E. Sabow: A Forensic Analysis Submitted to the United States Congress. J Forensic Res 7: 362. doi: 10.4172/2157-7145.1000362

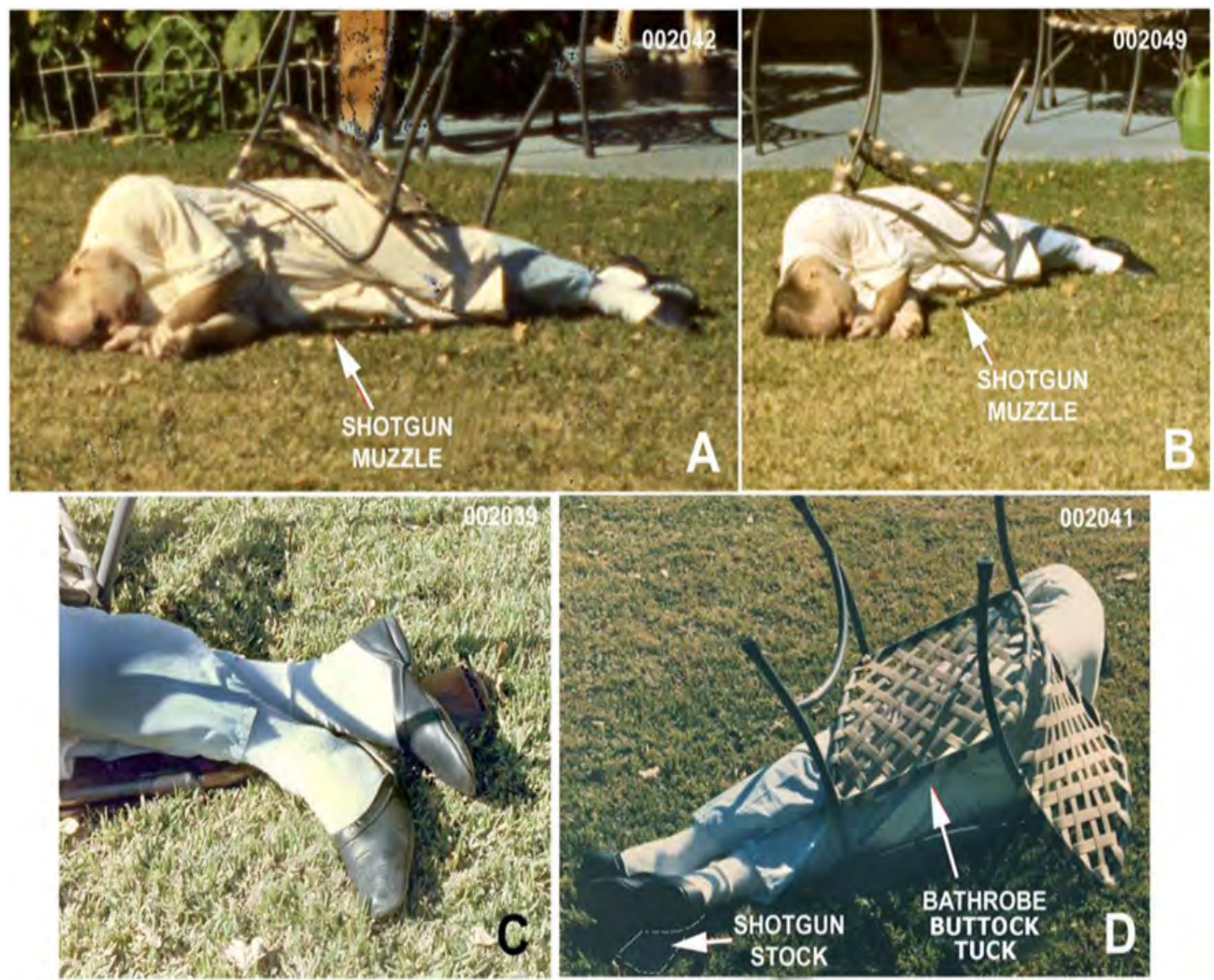

Figure 1: Photographs from the death scene. A: The body in the backyard of his home. The shotgun is in front of him with his legs over the shotgun stock. A patio chair is on top of the body. The bathrobe is tucked between his legs to the crotch. B: Another view of the body. C: View of the victim's legs and feet with the shotgun stock underneath. D: View of the body from the rear. The bathrobe was tucked between the legs to the buttocks.

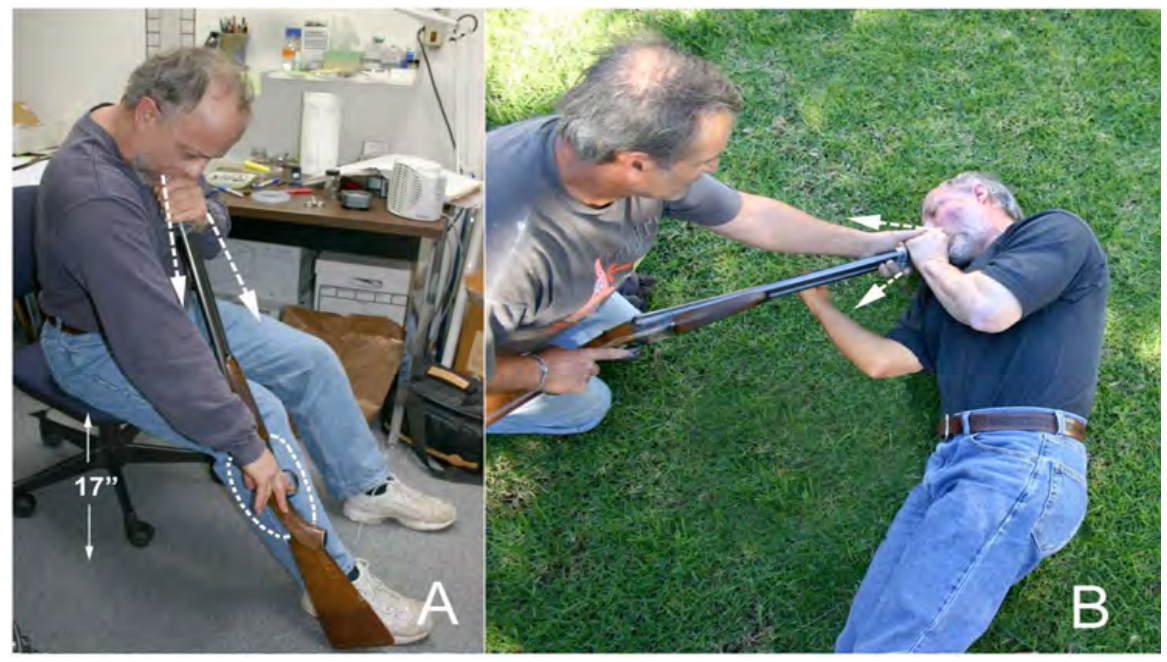

Figure 2: A: Re:enactment of the suicide scenario with the victim sitting in a chair and inserting the shotgun into his mouth; the muzzle is gripped by the left hand while the right hand is at the trigger. The shotgun was found under the right leg (Figure 1). This would place the shotgun in the re:enactment on the outside of the right leg. In this scenario, gas escape from the mouth would spray the thighs (white arrows) with GSR, BSR and blood/tissue on the front of the bathrobe and/or the thighs of the pajama bottom. The white dashed line on the lower right leg outlines the probable area of GSR deposition if there were breech and trigger housing gas leakage by the shotgun. B: Re:enactment of part of the homicide scenario where the shotgun is inserted into the mouth of the victim by an assailant; in order for the muzzle to remain in the mouth when the shotgun is fired, the stock of the shotgun would have to be supported. Evidence for a rapid exit (recoil) of the muzzle of the shotgun in this scenario is the rotation and drop to the grass of the left hand before receiving blowback blood (see text). The right hand was not exposed to detectable GSR. However, blood spatter is on the right hand which would also place this hand close to the nose and mouth, the only sources of blood shedding. The death scene photographs (Figure 1) show the victim's right hand near the mouth. White arrows: route of the gas expellation (early blowback) while the shotgun muzzle was in the Colonel's mouth. 


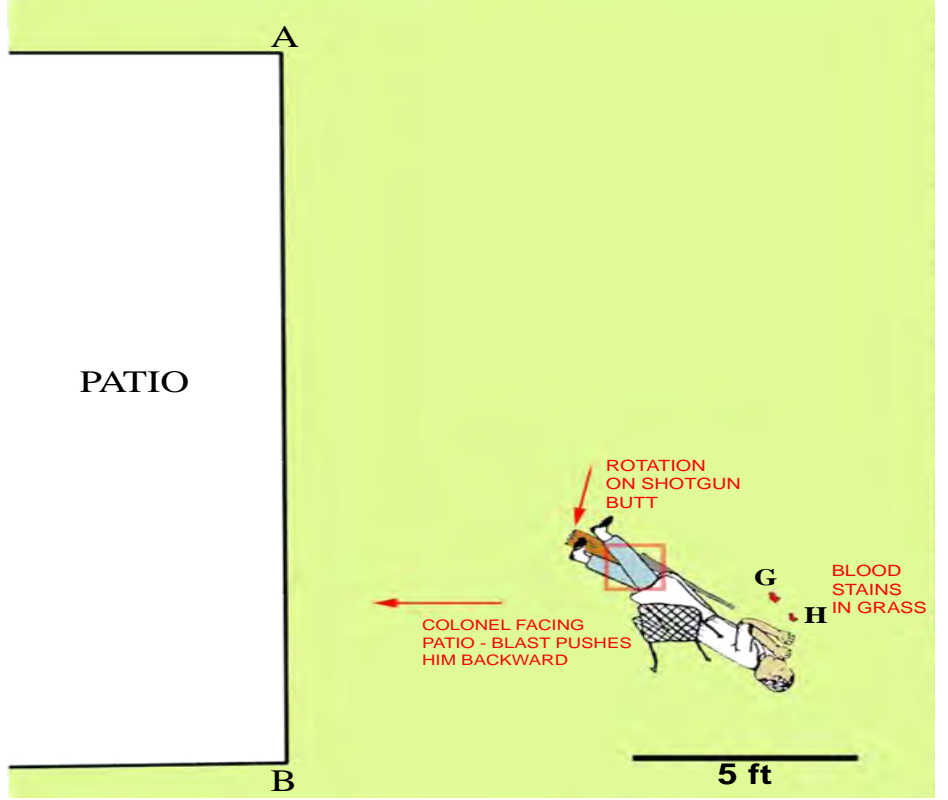

Figure 3: The death scene drawn to scale using the measurements provided by the Naval Investigative Service on the scene drawing. The body graphic is the one originally rendered in the scene drawing, but sized and rotated to the scaled position. The grass bloodstain positions $\mathrm{G}$ and $\mathrm{H}$ were adjusted according to those measurements on the scene drawing and their positions are shown in relation to the body. Color was added by author. The scene is portraying the suicide scenario. The estimated original position of the patio chair (red square) in the suicide scenario is based on the shotgun pivoting on its stock to the location under the victim's legs and feet, as shown with the Colonel being propelled by the shotgun blast backward and to his right. He somehow straightens his body upon allegedly falling to the ground.

positioned by the assailant under the Colonel's legs and a patio chair placed on the body (Figure 1) in order to generate the appearance of suicide.

The Nordby reports [2,4], both of which concluded suicide, were not convincing due to many flaws which will be discussed. The author conducted an independent study with the assistance of Dr. David Sabow, the brother of the Colonel and a forensic neurologist, which resulted in this report to Congressman Duncan Hunter. The gunshot residue (GSR), backspatter residue (BSR), bloodstain examination and crime scene observations are presented here.

MacLachlan [6] examined the pathology. Revealed in his study was evidence of a depressed right occipital skull fracture which was shown to have occurred prior to the intraoral shotgun discharge. The Colonel had received a strong blow by a club to the back of his head prior to the intraoral shotgun blast. The study presented here examines the GSR and BSR by scanning electron microscopy, the bloodstains on and around the body and the positions of the body and clothing.

\section{Gunshot and Back Spatter Residues}

Two general particle types involved in this case can be detected by scanning electron microscopy (SEM)/energy dispersive X-ray spectroscopy (EDS):

\section{Gunshot residue (GSR)}

These particles, produced by the firing of a gun, are usually composed of lead, antimony and barium in various combinations and originate from the primer of the cartridge. Other elements often associated with GSR are aluminium, silicon, sulphur, chlorine, potassium, calcium and iron. In addition, bullet-origin particles composed of copper, zinc and nickel are often associated with the primer-origin particles. Unjacketed bullet and some jacketed bullets will produce large amounts of lead particles [7] in GSR from both the breech and muzzle. For a shotgun, lead shot ablation coupled with heat would generate lead particles as they travel down the bore.

\section{Back spatter residue (BSR)}

These are particles produced by a contact or near contact shot to the head included in blowback. The interaction of the bullet, or in this case, lead shotgun pellets and hot gases with bone (calcium and phosphorus) will produce characteristic particles of lead-calcium-phosphorus and particles composed of bone [8]. Gunshot residue particles would also be associated with BSR.

\section{Gunshot residue associated with clothing}

Leakage of GSR-laden gases from the shotgun, if it occurs, would be from the breech area and perhaps the trigger housing of the Ithaca shotgun (Figure 4). There appear to be no published reports on breech GSR leakage of side-by-side double barrel shotguns. Once it is established that the shotgun has breech leakage of GSR-laden gas, the major part of the particle burden study is the examination of samplers taken from the Colonel's bathrobe and pajama bottom analyzed by SEM/EDS.

Martinez [9] notes "GSR can be readily detected and identified on clothing and in automobile interiors with the same simple sampling techniques as those used for collecting P-GSR [primer gunshot residue] from the hands. The results obtained proved to be a valuable investigative tool in reconstructing the possible events of firearms related crime and should not be overlooked by the forensic scientist". Unfortunately, this viewpoint is not universally accepted. Contrary opinions have been proffered by criminalists in case work. For instance, in the case 
Citation: Burnett BR (2017) The Homicide of United States Marine Corps Colonel, James E. Sabow: A Forensic Analysis Submitted to the United States Congress. J Forensic Res 7: 362. doi: 10.4172/2157-7145.1000362
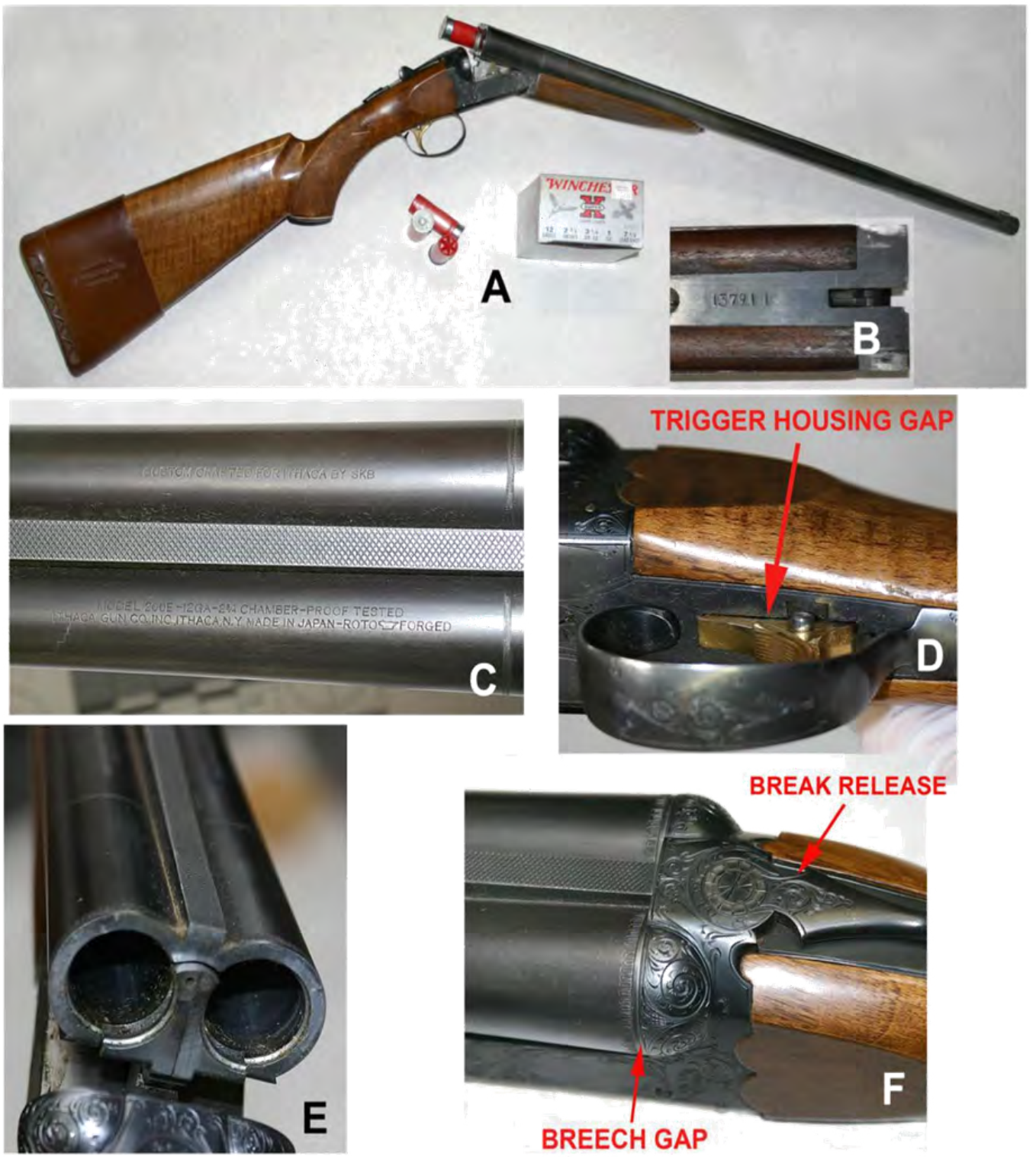

Figure 4: The shotgun. A: Full view of the Ithaca shotgun with the Winchester- ame Load box and cartridges used in the test of the shotgun. B: The serial number of the shotgun. C: Identification information on the barrels of the shotgun. D: The trigger area of the shotgun. The trigger housing gap is indicated. E: The opened breech of the shotgun. F: The closed breech area of the shotgun.

California v. Robert Blake (2005, Los Angeles, California), a criminalist stated in a memo, when asked to analyze sweatshirts for GSR, "explain to the detective that gunshot residue particle analysis cannot prove or answer his question. Any interpretation of the presence or absence of gunshot residue on surfaces other than bare hands is unfounded and possibly misleading". In the case California v. Phil Spector (2007, Los Angeles, California), another criminalist did not sample Spector's jacket sleeves for GSR, even though Spector likely washed his hands prior to sampling. If one of Spector's hands had been in close proximity to the revolver when it discharged, his jacket sleeve would have had GSR deposited on it. Heavy GSR deposition on one of the jacket sleeves versus the other would have been inculpatory [11]. Longterm persistence of GSR on clothing is known [12] and it cannot be establish that the shooting at issue was that which deposited GSR [13].
However, the history of an article of clothing as to recent launderings and the probability of exposure to GSR from another source should be evaluated for any item suspected of involvement in a shooting.

Niemeyer [14] described sampling and detection of GSR from the inside of a pocket where a recently fired pistol was secreted. There was no GSR detected on the sampler from the other pocket. Chavez, et al. [15] described the effect of washing GSR-contaminated clothing. Mann and Espinoza [12] assessed contamination of bow hunter hands by jackets that were worn during rifle hunting.

The author has had cases over the last twenty-five years where the assessment of GSR burden on clothing and other inanimate objects had litigation value. 
Citation: Burnett BR (2017) The Homicide of United States Marine Corps Colonel, James E. Sabow: A Forensic Analysis Submitted to the United States Congress. J Forensic Res 7: 362. doi: 10.4172/2157-7145.1000362

The suicide scenario would place the breech of the shotgun on the outside of the right leg (Figure 5A) which would likely deposit GSR (if the shotgun's breech leaks) on either the bathrobe (Figure $5 \mathrm{~B}$ ) or the pajama bottom (Figure 5C). In addition, the victim in the suicide scenario would be leaning slightly forward in order to support the shotgun's stock on the ground (Figure $2 \mathrm{~A}$ ). In this position, blowback would occur within a second [8] after the shotgun discharge and spray the front and lap areas of the bathrobe with GSR and BSR. Concentrations of GSR on the outside right leg and GSR and BSR on the front and lap of the bathrobe would be the hallmarks of suicide.

In the homicide scenario (Figure 2B), there would be no focal (heavy relative deposition) GSR deposited on the bathrobe since the shotgun breech would be away from the body and the blowback from the mouth would also be directed away from the body. However, wind transport of GSR [16] and BSR onto the bathrobe is possible. If deposition by wind did occur, there might be a pattern to the distribution of GSR on the bathrobe.

\section{The GSR Samplers of the Hands of Colonel at the Death Scene}

One of the two types of SEM/GSR samplers available at the time was used to sample the Colonel's hands. These SEM/GSR samplers were
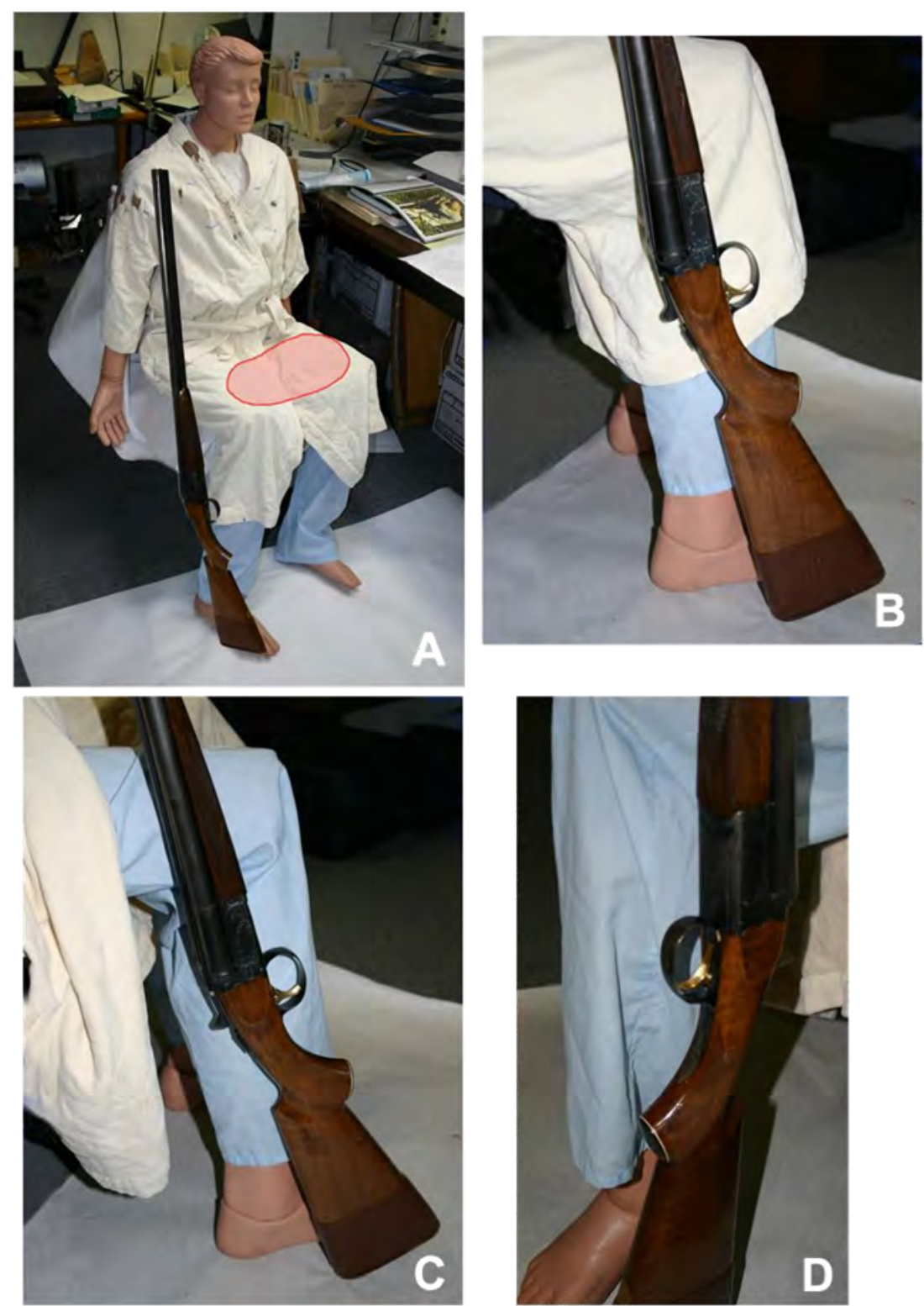

Figure 5: Re-enactment of the suicide scenario with a mannequin wearing the Colonel's clothes. A: Pink area: region where most of the back spatter in this scenario will hit the bathrobe. B: Close up of the mannequin's right leg with the shotgun in place. C: As in B, but the bathrobe is off the right leg. In this scenario, the pajama right leg in the calf area would receive the breech and trigger-housing GSR. However, the body at the scene indicated that the bathrobe fully covered the leg. D: Another variation of the suicide scenario with the shotgun between the legs. This scenario is unlikely for the reason described in $\mathrm{C}$ and the scene photographs show the shotgun was positioned outside the right leg. 
the concentration type [17] and one was photographed at the scene (Figure 6) while sampling the Colonel's left hand. These samplers were apparently not analysed at the time of the evidence processing and this sampler type currently is no longer used in GSR sampling and analysis. Video documentation of the scene processing by NIS criminalists showed swabs were also taken for GSR analysis after the SEM sampler sampling. The swabs were analysed by atomic absorption spectroscopy (AAS). The AAS analyses were performed at the California Department of Justice Laboratory in Riverside, California. The report [18] indicated that there were four swab samplers, two for each hand, back and palm.

\section{Analysis for GSR and BSR}

The GSR and BSR burdens associated with the bathrobe and perhaps the pajama bottom would differ depending on suicide or homicide of the Colonel.

\section{Analysis question one}

Does the shotgun produce GSR-laden gas leakage at the breech (Figure 4D) and from the trigger housing (Figure 4F) when fired? Before evaluating the second and third questions, verification is required that the 12 gauge shotgun produces breech GSR when fired that would contaminate the shooter.

\section{Analysis question two}

With the confirmation that the shotgun has breech/trigger housing leakage, a suicide scenario for the death of the Colonel would be supported by the detection of a large relative amount of GSR on the bathrobe corresponding to the lateral right calf region (Figure $2 \mathrm{~A}$ area on right leg outlined by dashed line; Figures $5 \mathrm{~A}$ and $5 \mathrm{~B}$ ) or the same

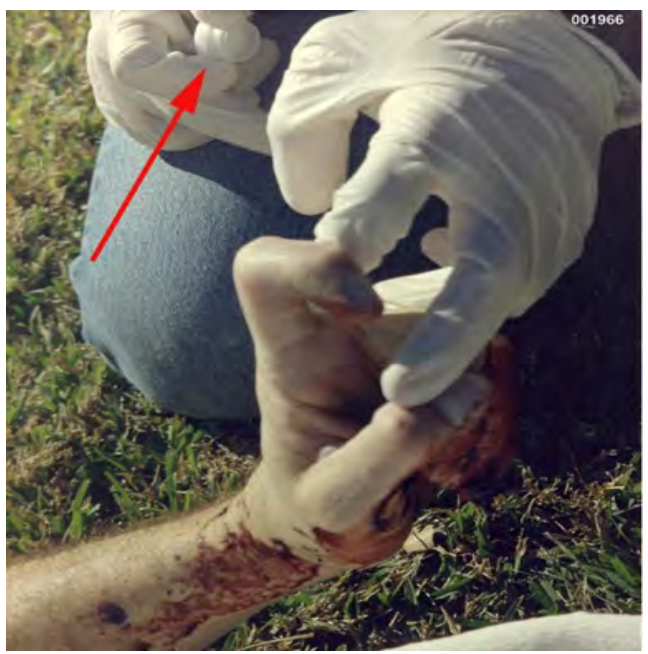

Figure 6: Photograph from scene showing the left hand of the victim in the process of GSR sampling. The arrow points to the GSR sampler. This is a concentration technique sampler made for SEM analysis, but was not analyzed. Swabs were also taken (no image, but in the video recording of the scene processing) and analyzed by atomic absorption spectroscopy.inserted into the mouth of the victim by an assailant; in order for the muzzle to remain in the mouth when the shotgun is fired, the stock of the shotgun would have to be supported. Evidence for a rapid exit (recoil) of the muzzle of the shotgun in this scenario is the rotation and drop to the grass of the left hand before receiving blowback blood (see text). The right hand was not exposed to detectable GSR. However, blood spatter is on the right hand which would also place this hand close to the nose and mouth, the only sources of blood shedding. The death scene photographs (Figure 1) show the victim's right hand near the mouth. White arrows: route of the gas expellation (early blowback) while the shotgun muzzle was in the Colonel's mouth. region on the pajama leg (Figure 5C). The shotgun placed between the legs (Figure 5D) in this scenario is unlikely, but is the position hypothesized by Nordby in his second report [4]. The positions of the bathrobe on the body of the Colonel and the shotgun under his right leg (Figure 1) suggest if this was a suicide, the shotgun would be lateral to the right side of the body at the time of discharge. Considering the position of the body, bathrobe and the shotgun, the simulations depicted in Figures 2A and 5A are likely for the suicide scenario. If the bathrobe was not covering the pajama legs, a heavy GSR burden would be on lateral right calf of the pajama leg (Figure 5C). Are there such concentrations of GSR on the bathrobe or pajama bottom?

\section{Analysis question three}

In the suicide scenario, the major exit for the gas in blowback is the sides of the mouth around the barrel of the shotgun and to lesser extent the nose. The exiting gases from the mouth and nose (white arrows, Figure 2A) would be directed onto the front of the bathrobe and likely produce a heavy deposition of GSR and BSR on the thigh areas of the bathrobe (pink area of Figure 5A) or the pajama bottom of the victim (if the bathrobe did not cover this area, as shown in Figure 5C). In a homicide scenario, the exit of the gas from the mouth would be away from the body (white arrows, Figure 3B). Do the thigh areas of the bathrobe or the pajama bottom lap areas have heavy BSR and GSR burdens?

\section{The Shotgun Tests}

The left barrel of the Ithaca 12 gauge shotgun was used in all tests. The ammunition used in the shotgun at the time of the victim's death was unavailable. Similar ammunition was obtained for the tests: Winchester-Game Loads 12 gauge, 2 3/4 inches, 3 1/4 Dr. Eq., 1 oz., 7 1/2 lead shot (Figure 4A).

The SEM samplers used for sampling all the items in this examination were made of $13 \mathrm{~mm}$ diameter aluminum platforms upon which $1.5 \mathrm{~mm}$ thick graphite disks were affixed. On the graphite disk, a graphite-impregnated double-sticky tape was applied. The sticky surface of the sampler was dabbed onto the evidence item. The sampler was placed directly into the specimen chamber of the scanning electron microscope where it was viewed and analyzed. Some of the samplers were carbon coated. Two scanning electron microscopes were used in this study. For the non-automated analyses, an ETEC Autoscan scanning electron microscope was used with a Kevex thin-window EDS detector. The automated analyses were performed in the laboratory of Dr. Jozef Lebiedzik (Advanced Research Instruments Corporation, Golden, CO, USA).

\section{Shotgun Breech/Trigger Housing Leakage}

The first test of the shotgun was to determine if the breech and the trigger housing leaks GSR. The exterior of the shotgun was thoroughly cleaned. Following the cleaning, the shotgun breech was wrapped by a cotton cloth. The cotton breech wrap (sample I-1) was removed immediately prior to the wrapping of the breech test cloth (sample J-1) at the range. Other control samples were taken as described below.

No firearms were discharged at the indoor range for twelve hours prior to this test. The shooter wore a DuraClean polyester glove. Only one shot was fired. Summary of the samples (60 dabs/sample):

I-1: Control cotton wrap of the shotgun breech prior to the final breech wrap (sample J-1).

I-2: A polyester DuraClean polyester glove that was put on the 
Citation: Burnett BR (2017) The Homicide of United States Marine Corps Colonel, James E. Sabow: A Forensic Analysis Submitted to the United States Congress. J Forensic Res 7: 362. doi: 10.4172/2157-7145.1000362

Page 7 of 20

shooter's right hand prior to entering the shooting range building. The glove was carefully removed and stored just prior to putting on the test glove, J-3.

I-3: A cotton witness cloth, $20 \times 20 \mathrm{~cm}$ exposed on the back bench of the range (approximately 5 feet from the shooting stall). Five minutes after the shot, this cloth was folded and placed in a sample bag.

I-4: A cotton cloth $(8 \times 20 \mathrm{~cm})$ that was taken out of its plastic bag at the range, exposed on the back bench for approximately 3 minutes prior to the shot and then refolded and placed back in its plastic bag.

I-5: A cotton cloth $(8 \times 20 \mathrm{~cm})$ placed on the shooting platform, under and to the left of the shotgun. prior to the shot. The distance of the breech/trigger of the shotgun when fired was approximately $50 \mathrm{~cm}$ from the center of the cloth surface. The cloth was folded and placed in a plastic bag immediately after the shot.

J-1: A cotton cloth wrapped around the breech of the shotgun to intercept GSR generated by breech leakage.

J-2: Control sampler, which was dabbed on J-3 DuraClean polyester glove a minute prior to the shotgun discharge.

J-3: The DuraClean polyester glove worn on the trigger hand after the firing of the shotgun.

It was apparent from the results of the analysis of the samplers that GSR-laden gas emanates from the breech and trigger housing (Table 1). In normal firing of the shotgun, the forefinger would be entirely across the trigger (Figure 2B). But in the suicide scenario, the finger or thumb would approach the trigger obliquely (Figure $2 \mathrm{~A}$ ) and there might be only partial exposure to the GSR laden gases from the breech area of the shotgun. Could the lack of detected GSR on the right hand be due to a non-uniform release of GSR-laden gas from the trigger housing?

In the final test of this series, two persons were required: one to hold the shotgun and the other to depress the trigger. Just after placing the polyester glove on the shooter's hand (only the wrist edges of the glove were handled), 60 dabs of the glove surface were taken with each GSR sampler. The ventilation system of the range was not working. The shotgun was fired and glove quickly collected after each shot (turned inside out from the wrist during the removal) and placed in a plastic bag for later sampling. In each test series, the trigger was depressed from a different angle. The gloves, N-2, P-2 and Q-2, were sampled in the laboratory, 60 dabs per item.

The samples:

N-1: Sixty control dabs of the glove while on the hand of the shooter at the range.

N-2: A forefinger from the left side of the shotgun to depress the trigger.

P-1: Same as sampler N-1.

P-2: A thumb from the left side of the shotgun to depress the trigger.

Q-1: Same as sampler N-1.

Q-2: A thumb from the right side of the shotgun to depress the trigger.

The results of these SEM/EDS analyses indicate that regardless of the position of the hand and fingers in the depression of the trigger, GSR deposition occurs upon firing the shotgun. The data for this experiment series are presented in Table 2.

\begin{tabular}{|c|c|c|}
\hline Sample & Description & Number GSR/Field \\
\hline I-1 & Bench Wrap Control & 0.5 \\
\hline I-2 & Facility Glove & 1.3 \\
\hline I-3 & Back Bench Cloth & 0.4 \\
\hline I-4 & Control & 0.1 \\
\hline I-5 & Shooting Bench Cloth & 0.4 \\
\hline J-1 & Breech Wrap & 28.2 \\
\hline J-2 & Trigger Glove Control & 0 \\
\hline J-3 & Trigger Glove & 13.6 \\
\hline
\end{tabular}

Table 1: Results of the testing of the breech and trigger housing of the shotgun GSR includes particles of all elemental compositions of GSR, including lead-only particles. Twenty fields at $300 \mathrm{X}$ were counted per sample.

\begin{tabular}{|c|c|c|}
\hline Sample & Description & Number GSR/Field \\
\hline N-1 & Control & 1.1 \\
\hline N-2 & Trigger Forefinger & 2.55 \\
\hline P-1 & Control & 0.55 \\
\hline P-2 & Trigger Thumb & 2.4 \\
\hline Q-1 & Control & 0.75 \\
\hline Q-2 & Trigger Forefinger & 2.45 \\
\hline
\end{tabular}

Table 2: Results of the SEM/EDS analysis from the sample of the oblique trigge depress experiments; the controls showed a burden of GSR due to a failed ventilation system of the indoor range. Despite this contamination problem, the tested gloves were sufficiently populated with additional GSR to indicate that regardless of how the trigger was pressed; the hand that depressed the trigger would become contaminated with GSR. GSR includes all elemental compositions of GSR, including lead-only particles. Twenty fields at 300X were counted per sample.

The DCI Forensic Laboratory of South Dakota tested the Ithaca shotgun in the position as depicted in the suicide scenario (i.e., the muzzle directed up, Figure 5A). The Winchester -Game Load was the test ammunition. This was done at an outdoor range. A clean cloth glove was used for each test, in which the trigger was depressed by the normal position and tests were made by oblique pressing of the trigger with either the forefinger or thumb of the right hand. The report [19] for these tests noted a wind speed of approximately 12 miles/hour during the tests. The samples were analyzed at the RJ Lee Group's laboratory in Pennsylvania [20]. These data are presented in Table 3.

\section{Sampling and Testing of the Bathrobe and Pajama Bottom for GSR}

The samplings of the bathrobe utilized GSR samplers as described above. Nine GSR samplers, K-1 through K-9 were applied, 60 dabs per sampler per region of the bathrobe (Figure 7A). Nine GSR samplers, $\mathrm{H}-1$ through $\mathrm{H}-9$ were applied, 60 dabs per region, on the pajama bottom (Figure 7B and 7C).

The samplers were analyzed by automated SEM at 180X. As much as $40 \%$ of each sampler surface was scanned. The results are presented in Table 4

A second series of analyses of the $\mathrm{K}$ samplers, independent of the first series was done (Table 5). During the first analyses of the $\mathrm{K}$ samples, cotton fibers picked up along with the inorganic particles were charging. This caused electron beam deflection and particles were likely missed. The $\mathrm{K}$ samplers were carbon coated and six of these samplers reanalysed. Included in the second series of analyses are assessments of calcium-phosphorus ( $\mathrm{CaP}$ - bone), lead-phosphorus ( $\mathrm{PbP}$ - the geochemical end-point for soil lead) and lead-phosphoruscalcium ( $\mathrm{PbP} \mathrm{Ca}$ - bullet/shot lead + bone). The latter particle type, is a characteristic product of contact/near contact gunshot to a head that is found in the resultant back spatter [8]. 
Citation: Burnett BR (2017) The Homicide of United States Marine Corps Colonel, James E. Sabow: A Forensic Analysis Submitted to the United States Congress. J Forensic Res 7: 362. doi: 10.4172/2157-7145.1000362

Page 8 of 20

\section{Results and Discussion of the GSR and BSR Tests}

\section{Gunshot residue samples of the victim's hands at the scene}

Gunshot residue sampling of the victim's hands was performed at the scene. It was apparent from the GSR report [18] atomic absorption spectroscopy (AAS) was used to analyse these samples. A major criticism of the AAS technique, which ultimately led to it to no longer being used for GSR analysis by crime laboratories for this application, is elemental associations cannot be determined. Automated SEM/EDS is more sensitive [21]. A video taken during the scene processing showed the criminalist, after dabbing the victim's hands with concentrationtechnique GSR samplers [17], swabbed the same hand areas with cotton-tipped applicators. It was these applicators that were analyzed by AAS for GSR metals. The reliability of this double sampling technique, specifically the swabbing for AAS following the SEM sampler dabbing has been shown to be even more unreliable for the AAS analysis [22]. The dabbing with the GSR SEM samplers prior to the swabbing removes GSR which likely contributed to no GSR elements detected on the right hand swabs by AAS. The left hand, which likely included the soot areas (Figure 8) were sampled by both sampler types.

\begin{tabular}{|c|c|c|c|}
\hline Sample & Description & $\begin{array}{c}\text { Number } \\
\text { Characteristic }\end{array}$ & $\begin{array}{c}\text { Number } \\
\text { Consistent }\end{array}$ \\
\hline 12 & Glove Control & 0 & 0 \\
\hline 13 & Glove Control & 0 & 0 \\
\hline 15 & Glove-R Hand Norm Position & 6 & 4 \\
\hline 16 & Glove-R Hand Norm Position & 8 & 3 \\
\hline 18 & Gove-R Hand Thumb & 2 & 0 \\
\hline 19 & Gove-R Hand Thumb & 1 & 2 \\
\hline 20 & Gove-R Hand Index Finger & 0 & 2 \\
\hline 22 & Gove-R Hand Index Finger & 0 & 0 \\
\hline
\end{tabular}

Table 3: Results of the SEM/EDS analyses from the samplers of the gloves taken by the DCI Forensic Laboratory and analyze the RJ Lee Group, Inc. [20]. Overall these data confirm those of this study (Table 2). However, the low numbers of reported GSR particles are likely due to a wind of 12 miles/hour at the range that prevented much of the GSR deposition on the cloth gloves.
The AAS data were not presented in the report and the author's name had been redacted from the copy reviewed. "The gunshot residue collection kit from Sabow was analyzed for the elements antimony and lead by atomic absorption spectrophotometry. These elements can be found in gunshot residues. Very high levels of antimony and lead were found on the palm and back of the left hand samples, while samples from the right hand were negative. This could be due to the left hand being near the muzzle of the discharging shotgun".

\section{Breech and trigger-housing leakage}

The shotgun has breech and trigger-housing leakage. This was determined in this study (Tables 1 and 2) and the tests performed by the DCI Forensic Laboratory [19] and analyzed by the RJ Lee Group [20].

The data presented in Table 3 provide numbers substantially less than those found in the present study (Table 2). It is apparent that a wind of 12 miles/hour [19] at the range prevented deposition of much of the GSR [16] produced by the breech and trigger housing upon the firing of the 12 gauge shotgun.

Regardless of the wind issue, it is probable that objects such as the bathrobe or pajama bottom and the hand of the shooter; either the victim (in the suicide scenario) or assailant (homicide scenario) near or in contact with the Ithaca shotgun breech and trigger areas will be contaminated with GSR.

No wind was recorded for El Toro area on January 22, 1991 until 1000 [23]. This is supported by the leaves on the lawn remaining stationary at the scene throughout the photography period of the crime scene.

\section{The nature of close-range shots to heads}

The evidence presented in this case shows two distinct events occurred following the intraoral shotgun discharge. DiMaio [24], notes with a contact or near contact to a head there is often a momentary dissection (gas-filled void) between the scalp and the skull. This is followed by collapse of this space which results in (initial) blowback. But, in this case the shotgun blast was intraoral.

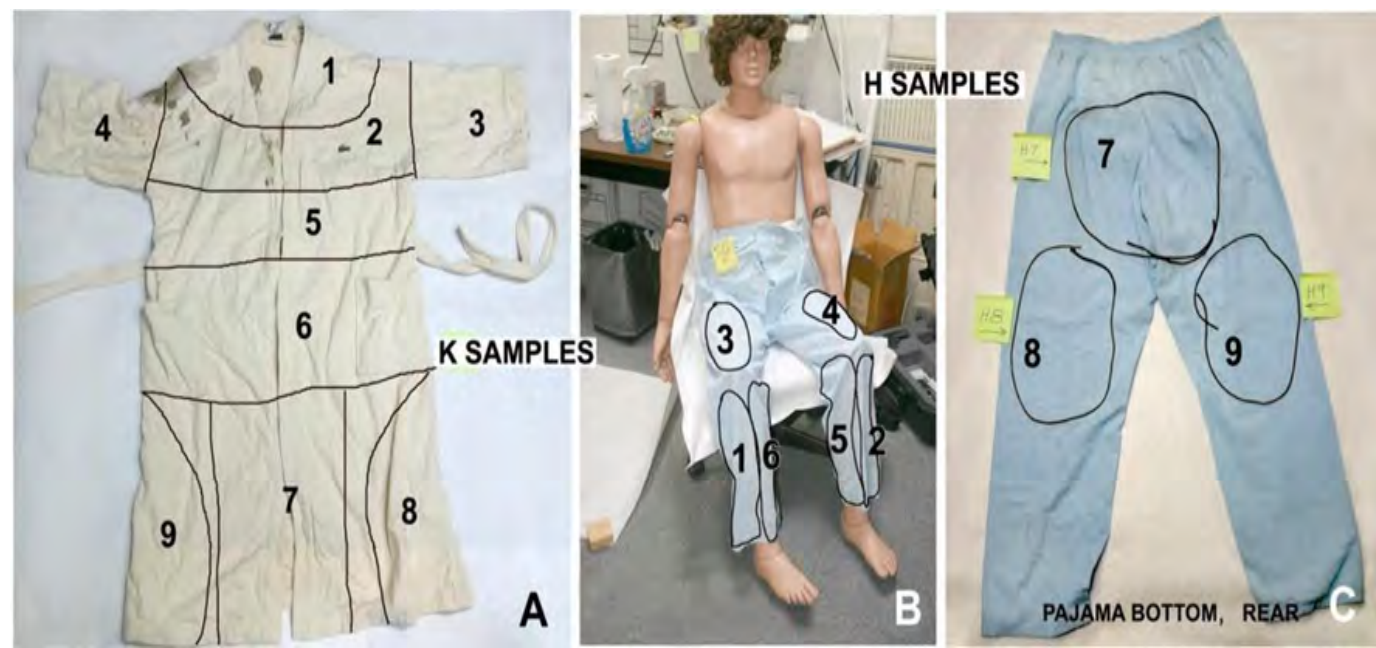

Figure 7: SEM sampler series $\mathrm{H}$ and K. Sixty dabs per sample. A: Sample regions of the bathrobe (samples K-1 through K-9). B: The front areas of the pajama bottom (Samples $\mathrm{H}-1$ through $\mathrm{H}-6$ ). C: The back of the pajama bottom showing the SEM tape lift area $\mathrm{H}-7$ (buttocks), $\mathrm{H}-8$ (left rear thigh) and $\mathrm{H}-9$ (right rear thigh). 
Citation: Burnett BR (2017) The Homicide of United States Marine Corps Colonel, James E. Sabow: A Forensic Analysis Submitted to the United States Congress. J Forensic Res 7: 362. doi: 10.4172/2157-7145.1000362

Page 9 of 20

The oral cavity is proposed to be analogous to the temporary cavitation described by DiMaio. There is likely little difference between intraoral and scalp/skull early blowback and intraoral blowback. The second blowback event is an exhalation of the gas that was injected into the skull, which follows and transitions from the initial or early blowback (mostly soot and GSR) to a bloody blowback. This is likely especially prominent when there is no exit wound [8]. The present study shows that the intraoral 12 gauge shotgun blast without an exit wound presents the early blowback phase that is mostly made up of soot and GSR (Figure 8). This transitions into a second phase blowback of gas with blood, other tissue debris, BSR and GSR. Additional evidence for a two-phase blowback from the victim will be discussed.

\section{The bathrobe and pajama bottom}

The results of the analyses presented here and by the RJ Lee Group
[20] indicate the shotgun leaks GSR from the breech and trigger housing when fired.

The results of the analyses of the eighteen tape lifts from the bathrobe and pajama bottom are presented in Tables 4 and 5. For the bathrobe (the $\mathrm{K}$ samples) only two characteristic (lead-antimony -barium (PbSbBa)) particles were detected (Table 4) and one lead-antimony particle (Table 5). The lead-only particles represent a significant problem in GSR interpretation due to many possible environmental sources, including piston-engine aircraft exhaust (the Colonel's house was in the flight path of the El Toro MCAS runway). So, the levels of lead only particles found associated with the bathrobe cannot be attributed solely or even partly to the shotgun discharge unless those levels are compared with samples of articles of clothing that have not been exposed to an environment of GSR.

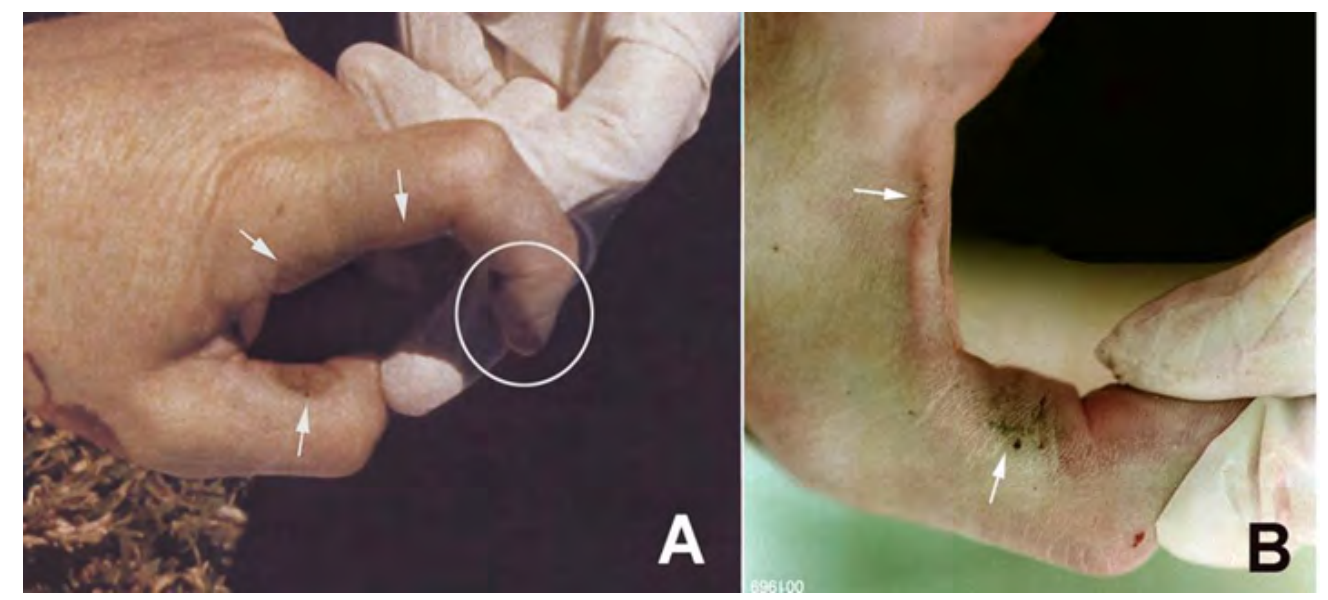

Figure 8: Gunshot soot (arrows) on the left hand of the Colonel; photographs taken at the scene. The soot deposition likely occurred as the muzzle of the shotgun passed by the left hand when it recoiled out of the Colonel's mouth. A: The tip of the index finger shows a patterned bloodstain (circle). Arrows point to soot deposits. B: Higher magnification photograph the thumb and part of the posterior hand showing discrete soot particles (arrows).

\begin{tabular}{|c|c|c|c|c|c|c|c|c|c|}
\hline \multirow[b]{3}{*}{ Bathrobe } & \multirow[b]{3}{*}{$\mathrm{K}-1$} & \multicolumn{8}{|c|}{ Particle ID } \\
\hline & & \multicolumn{2}{|c|}{$\mathrm{PbSbBa} \#$ EST } & \multicolumn{2}{|c|}{$\mathrm{PbBa} \mathrm{PbSb} \# \mathrm{EST}$} & \multicolumn{2}{|c|}{$\mathrm{Pb}^{\star} \# \mathrm{EST}$} & \multicolumn{2}{|c|}{$\mathrm{PbP}$ \# EST } \\
\hline & & 0 & - & 0 & - & 2 & 5 & 1 & 3 \\
\hline & $\mathrm{K}-2$ & 0 & - & 0 & - & 4 & 11 & 0 & - \\
\hline & $\mathrm{K}-3$ & 1 & 3 & 0 & - & 3 & 8 & 0 & - \\
\hline & $\mathrm{K}-4$ & 0 & - & 0 & - & 2 & 5 & 0 & - \\
\hline & K-5 & 0 & - & 0 & - & 5 & 13 & 0 & - \\
\hline & $\mathrm{K}-6$ & 0 & - & 0 & - & 4 & 11 & 0 & - \\
\hline & $\mathrm{K}-7$ & 0 & - & 0 & - & 8 & 22 & 1 & 3 \\
\hline & $\mathrm{K}-8$ & 1 & 3 & 0 & - & 4 & 11 & 0 & - \\
\hline & $\mathrm{K}-9$ & 0 & - & 0 & - & 2 & 5 & 0 & - \\
\hline \multirow[t]{9}{*}{ Pajama Bottom } & $\mathrm{H}-1$ & 0 & - & 3 & 8 & 26 & 71 & 6 & 16 \\
\hline & $\mathrm{H}-2$ & 1 & 3 & 0 & - & 10 & 27 & 0 & - \\
\hline & $\mathrm{H}-3$ & 0 & - & 1 & 3 & 14 & 38 & 0 & - \\
\hline & $\mathrm{H}-4$ & 1 & 3 & 3 & 8 & 12 & 33 & 3 & 8 \\
\hline & $\mathrm{H}-5$ & 1 & 3 & 8 & 22 & 45 & 123 & 3 & 8 \\
\hline & $\mathrm{H}-6$ & 0 & - & 9 & 26 & 92 & 257 & 3 & 8 \\
\hline & $\mathrm{H}-7$ & 4 & 11 & 5 & 14 & 46 & 126 & 2 & 5 \\
\hline & $\mathrm{H}-8$ & 0 & - & 2 & 5 & 6 & 16 & 1 & 3 \\
\hline & $\mathrm{H}-9$ & 0 & - & 1 & 3 & 9 & 25 & 2 & 5 \\
\hline
\end{tabular}

Table 4: Results of the automated SEM/EDS analysis of the samples from the bathrobe (K samples) and the pajama bottom (H samples); samples analyzed by Dr. Jozef Lebiedzik. 
The calcium-phosphorus (actually calcium phosphate) or bone particles on the bathrobe (Table 5) may be from blowback. But ground bone, bone meal is used as a fertilizer additive. The association of lead with calcium phosphorus would have been created by the blowback event. The lack of lead-associated calcium-phosphorus particles indicates the calcium phosphorus particles identified in these analyses are from an environmental source.

The lead-phosphorus particles have a quite different origin. These particles are the endpoint of the geochemical transition of soil lead [25]. The presence of lead-phosphorus particles on the bathrobe indicates these and other lead-bearing particles, without antimony or barium association, likely have an environmental source.

The estimated GSR burdens from the pajama bottom samplers are different from the bathrobe (Tables 4 and 5). These samplers document an exposure to GSR of the pajama bottom the bathrobe did not receive. The two-component GSR (lead-antimony and lead-barium) particles are generally present on the pajama bottom, but only one particle of this type was found on the bathrobe. There are also more of the characteristic (lead-antimony-barium, $\mathrm{PbSbBa}$ ) particles on the pajama bottom than on the bathrobe. The lead-only particle burden of the pajama bottom is also large compared to the bathrobe. These additional lead particles likely are GSR. The assumption in the comparison of the GSR burdens of these two articles of clothing is both have nearly identical exposure histories prior to the shotgun blast and the pajama bottom was not contaminated by the other clothing items (underwear and t-shirt) that shared the same storage container.

The suicide scenario shotgun position (Figure 2A) proposes the Colonel fell back and to his right off the patio chair following the intraoral shotgun blast $[2,4]$. During the fall from the patio chair, the shotgun pulled from his mouth and the stock ended up beneath his legs and feet. He somehow straightens his flaccid body. The body position will be discussed in more detail. The position of the shotgun in relation to the body suggests it was against the right leg as shown in Figure 2A at its firing. The scene photographs also show the victim's bathrobe tucked between his legs (Figure 1A). Thus, for the suicide scenario, the bathrobe would have to be covering the Colonel's legs (Figure 5A) and intercept the GSR from both the breech and the trigger housing at region K-9 (Figure 7A).

In the suicide scenario, with the bathrobe covering the Colonel's legs to its full extent as shown in the scene photographs (Figure 1A and 1B) at least the areas K-6 and K-7 (Figure 7A) should have evidence of extensive contamination by blowback (back spatter) of both GSR and BSR. No particle burdens supportive of this event were observed.
The GSR evidence of the bathrobe and the pajama bottom show:

1. The bathrobe was not in a position to receive significant GSR and BSR when the shotgun was discharged. The bathrobe was likely partly folded, parts turned inside out and "hiked up" on the victim so that it was contaminated only with a few GSR particles. The bathrobe likely covered little, if any, of the pajama bottom when the intraoral shotgun blast occurred.

2. The pajama bottom, because of the lack of cover by the bathrobe, was contaminated with GSR particles (Table 4). Curiously, one of the heaviest GSR contaminations was the buttocks region (sample H-7, Figure $7 \mathrm{C}$ ) of the pajama. This may have occurred due to the GSR-laden cloud from the shotgun blast drifting over the lower abdomen area or contact was made by the GSR-contaminated assailant (homicide scenario). The pajama covering the lower abdomen was not sampled. Regions $\mathrm{H}-4, \mathrm{H}-5$ and $\mathrm{H}-6$ from the pajama bottom (Figure $7 \mathrm{~B}$ ) also had relatively heavy GSR contamination. These three regions were apparently also exposed to the shotgun-produced GSR cloud when it discharged from the Colonel's mouth and/or the shotgun's trigger housing and breech. With the Colonel lying on his right side in the homicide scenario, regions $\mathrm{H}-1$ and $\mathrm{H}-3$ of the pajama bottom would receive less surface exposure to GSR contamination. Indeed, these areas show less contamination than H-5, H-6 and H-7. The back of the thighs of the pajama bottom (H-8 and H-9) were possibly shielded from the GSR source and received the least contamination. Alternatively, the pajama bottom became contaminated with GSR when the shooter, with GSR-contaminated hands, participated in the staging of the body.

In the suicide scenario, the thighs of the bathrobe or perhaps the pajama bottom (if not covered by the bathrobe) would be heavily contaminated with GSR and BSR, which was not the case for either item. However, Nordby [4] presented a report to the United States Department of Defense and Congressman Duncan Hunter, Chairman of the Armed Services Committee in 2006 which refutes the first report on GSR in this case [26] and the conclusion the Colonel was the victim of homicide. Gunshot residue burdens without support data or images from of the Colonel's clothing were briefly discussed in two of the pages from Nordby's 2006 report [4] which include the handdrawn and written figures shown in Figure 9. Nordby apparently used $\mathrm{X}$-ray fluorescence (XRF in the handwritten notes, Figure 9A and 9B) to detect lead, antimony and barium. He reports observing 0.5 micron to 10 micron diameter GSR particles, which must have been by SEM/EDS

\begin{tabular}{|c|c|c|c|c|c|c|c|c|c|c|c|c|c|}
\hline & & \multicolumn{12}{|c|}{ Particle ID } \\
\hline & & \multicolumn{2}{|c|}{$\mathrm{PbSbBa} \#$ EST } & \multicolumn{2}{|c|}{$\mathrm{PbBa} \mathrm{PbSb} \# \mathrm{EST}$} & \multicolumn{2}{|c|}{$\mathrm{Pb}^{\star}$ \# EST } & \multicolumn{2}{|c|}{ PbP \# EST } & \multicolumn{2}{|c|}{ CaP \# EST } & \multicolumn{2}{|c|}{$\mathrm{PbP} \mathrm{Ca} \# \mathrm{EST}$} \\
\hline \multirow{9}{*}{ Bathrobe } & $\mathrm{K}-1$ & 0 & - & 1 & 3 & 8 & 23 & 4 & 11 & 11 & 30 & 0 & - \\
\hline & $\mathrm{K}-2$ & 0 & - & 0 & - & 8 & 23 & 1 & 3 & 3 & 5 & 0 & - \\
\hline & $\mathrm{K}-3$ & - & - & - & - & - & - & - & - & - & - & - & - \\
\hline & $\mathrm{K}-4$ & 0 & - & 0 & - & 14 & 38 & 0 & - & 9 & 26 & 0 & - \\
\hline & $\mathrm{K}-5$ & 0 & - & 0 & - & 5 & 13 & 0 & - & 8 & 23 & 0 & - \\
\hline & $\mathrm{K}-6$ & - & - & - & - & - & - & - & - & - & - & - & - \\
\hline & $\mathrm{K}-7$ & 0 & - & 0 & - & 19 & 52 & 4 & 11 & 4 & 11 & 0 & - \\
\hline & K-8 & - & - & - & - & - & - & - & - & - & - & - & - \\
\hline & K-9 & 0 & - & 0 & - & 6 & 16 & 0 & - & 9 & 25 & 0 & - \\
\hline
\end{tabular}

Table 5: Results of the second analysis series performed by Dr. Lebiedzik for six of the $\mathrm{K}$ samples from the bathrobe is shown; along with the second analysis series, calcium-phosphorus (CaP), lead-phosphorus ( $\mathrm{PbP}$ ) and lead-phosphorus-calcium ( $\mathrm{PbP} \mathrm{Ca}$ ) burden were assessed. 

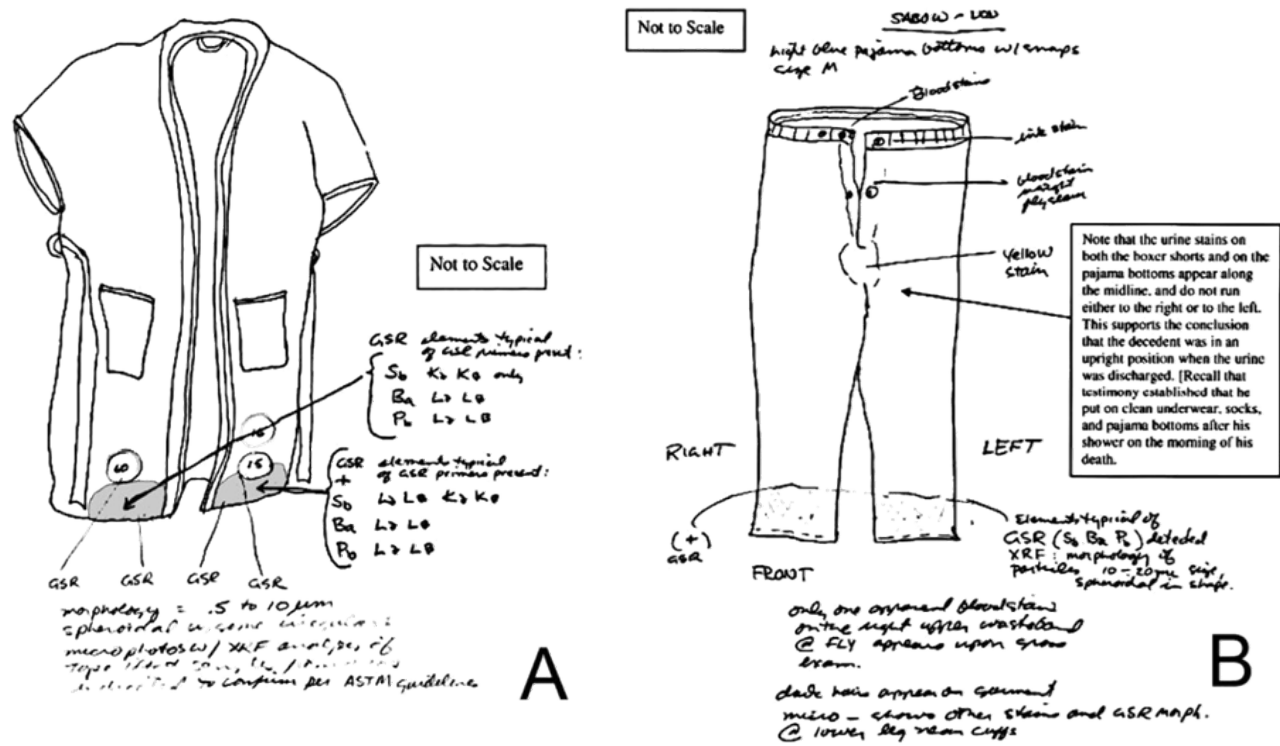

Figure 9: Drawings and handwritten notes showing the results of Nordby's GSR testing of the bathrobe and pajama bottom [4]. Portions of the figures are illegible in the source. A: Nordby's drawing of the bathrobe where he indicates he had found GSR concentrated along the lower front hem (shaded area). The lower margins of the bathrobe were enhanced by adding gray to the areas originally shaded, but lost in the copying. B: A similar drawing of the pajama bottom; a concentration of GSR was discovered by Nordby on the front cuffs of the pajama pants.

But without supporting images or spectra, it is questionable Nordby used SEM/EDS in his analysis.

Nordby [4] attributes his finding of GSR on the bathrobe lower hem and pajama bottom cuffs to the discharge of the shotgun between the Colonel's legs (Figure 5D) rather than on the lateral side of the right leg (Figures 2A, 5A and 5B) as would be indicate by the position of the shotgun with the body (Figure 1) in the suicide scenario. However, his conclusion does not support the suicide scenario, but does the homicide scenario. If the shotgun breech was positioned near either the bathrobe or pajama bottom between the Colonel's legs as suggested by Nordby, GSR should have been detected in areas H-5 and H-6 of the pajama bottom (Figure 7B, Table 4). Although GSR from pajama bottom region H-6 was detected (Table 4), it is not in sufficient quantity to have been deposited by the closely-associated Ithaca shotgun breech at discharge.

Figure 5D shows just how untenable Nordby's suicide scenario is with the shotgun placed between the Colonel's legs:

1. The bathrobe's lower exterior hem (Figure 9A) simply could not be exposed to the shotgun breech GSR since the bathrobe exterior would not cover the inner legs (Figure 5D) as would be necessary to be exposed to the shogun's breech discharge.

2. The shotgun's breech is too high on the pajama pant legs in the suicide scenario (Figure 5D) to have deposited GSR at the locations (Figure 9B).

The sampling described in this study (Figure 7) was apparently above those GSR deposits found by Nordby, if his results are to be believed. The only way for Nordby's GSR deposits (Figure 9) to have occurred and be consistent with the results presented in Tables 4 and 5 is for the GSR-contaminated shooter (homicide scenario) participated in the staging of the Colonel's body.

\section{The positions of the left and right hands at the shotgun blast}

In both scenarios presented, the left hand gripped the barrel near the muzzle at the victim's mouth when it fired. In the suicide scenario, the Colonel gripped the shotgun himself in the manner (Figure 2A). In the homicide scenario, the victim's left hand was held in the same position on the shotgun's muzzle by the assailant as shown in Figure 2B. The presence of soot on the left hand (Figure 8, arrows) means a heavy burden of muzzle GSR was deposited on the left hand when the shotgun fired. Indeed, GSR was reported present on the left hand [18]. The shotgun muzzle remained long enough in the victim's mouth that minute amounts of tissue blowback within the barrels\| [5] were observed.

In the suicide scenario, the right hand would be exposed to breech, not muzzle GSR (Figure 2A). Therefore, the right hand would be exposed to GSR contamination in both the suicide and homicide scenarios. No GSR was detected on the right hand, which was likely due to a flawed sampling procedure [22] and low sensitivity of AAS compared to SEM/EDS [21].

In the homicide simulation the left hand was at the shotgun muzzle so that the right hand would receive muzzle GSR in early blowback (Figure 2B). Early blowback occurred through the sides of the mouth when the shotgun was momentarily present (recoil pulled the shotgun muzzle out of the mouth) and before the left hand dropped to the ground which was when the right hand was exposed to GSR. The left palm also likely received soot and GSR which was subsequently covered by blood-laden blowback when the left hand returned to the ground.

\section{Bloodstains}

\section{The bloodstains in the grass - $\mathrm{G}$ and $\mathrm{H}$}

Mentioned previously and illustrated in the scene drawing (Figure 
Citation: Burnett BR (2017) The Homicide of United States Marine Corps Colonel, James E. Sabow: A Forensic Analysis Submitted to the United States Congress. J Forensic Res 7: 362. doi: 10.4172/2157-7145.1000362

Page 12 of 20

3) are the bloodstains $\mathrm{G}$ and $\mathrm{H}$ in the grass near the Colonel's body. A number of second-generation (i.e., prints directly from the negatives) scene photographs were made available to this study include the location of these two bloodstains, but with all, except one, close examinations and image enhancements, the alleged bloodstains could not be identified. The two scene photographs of a criminalist pointing to the bloodstains (Figure 10A of bloodstain G), proved impossible to discern the alleged bloodstains for these images. These bloodstains likely occurred with expirated blood, which was verified by one exceptional image (Figure 10B, arrows) where, with global enhancement in Photoshop, small, likely blood spatter can be seen which is consistent with expirated blood [27] on the grass blades.

\section{The bloodstains in the grass - under and in front of victim's} head

There was a large bloodstain under and in front of the Colonel's head. The high resolution of the images of these photographs played an important part in the analysis of this bloodstain. By enlarging areas of the grass around the head with images both before and after the body was turned on its back it is possible to position the head and left hand in relation to the bloodstain (Figure 11A). The positioning of the left hand in relation to the bloodstain indicates this hand acted as a barrier for the bloodstain (Figure 11B). The bloodstain itself (Figure 11C) can be divided into regions (Figure 11D) according to origin. At the 3 o'clock margin of this bloodstain the bathrobe on the victim's shoulder absorbed mostly serum from this bloodstain (BATHROBE WICKING, Figure 11D).

This bloodstain is composed mostly of blood that emanated from the mouth and nose. The blood had coagulated in the central part of the bloodstain on the left palm. The lower part of the bloodstain in the image (BLOWBACK (MOUTH) Figure 11D), although also emanating from the mouth was created by the bloody blowback from the intraoral shotgun blast.

\section{Bleeding from a right occipital scalp wound during body transport}

The Colonel's body was taken from the scene of death on the El Toro MCAS to the Orange County Sheriff/Coroner facility for autopsy. He was transported on his back. At the Coroner's facility one of the photographs taken before cleaning the body showed a ring of blood surrounding the right occipital region of the head (Figure 12A). The same area after cleaning is shown in Figure 12B. Upon gamma adjustment in Photoshop of the area over the right occipital region (Figure 12C), an abrasion can be seen with enlargement of that modified area in the photograph where hair appears to have been pushed into the wound (Figure 12D). This wound was missed by the medical examiner during the autopsy [1].

\section{The left hand and arm}

There are a variety of different bloodstains on the left arm and hand (Figure 13). The region on the radial wrist shows a splotchy bloodstain with an irregular margin (Figure 13A, EXPRIATED BLOOD and Figure 13B). The radial side of the forearm was not in contact with any obstructing surface as indicated by the irregular margin of the bloodstain. This is in contrast to the ulnar side of the wrist where the bloodstain has nearly a linear margin. The bloodstain on the ulnar side was limited by the flexor carpi radialis tendon which indicates that the ulnar forearm was rotated away from the mouth when the bloodstain was deposited. This blood was deposited by a spray so that overall it is a thin coating. Voids (originally bubbles) are seen throughout the bloodstain as well as splotchy features that are likely areas of blood mixed with mucus (Figure 13B). This bloodstain is from expirated blood.

The left hand of the victim also has a thick bloodstain that appears to cover the entire palm area as well as most of the distal dorsal fingers (Figure 13). The origin of this bloodstain is indicated by the patterned

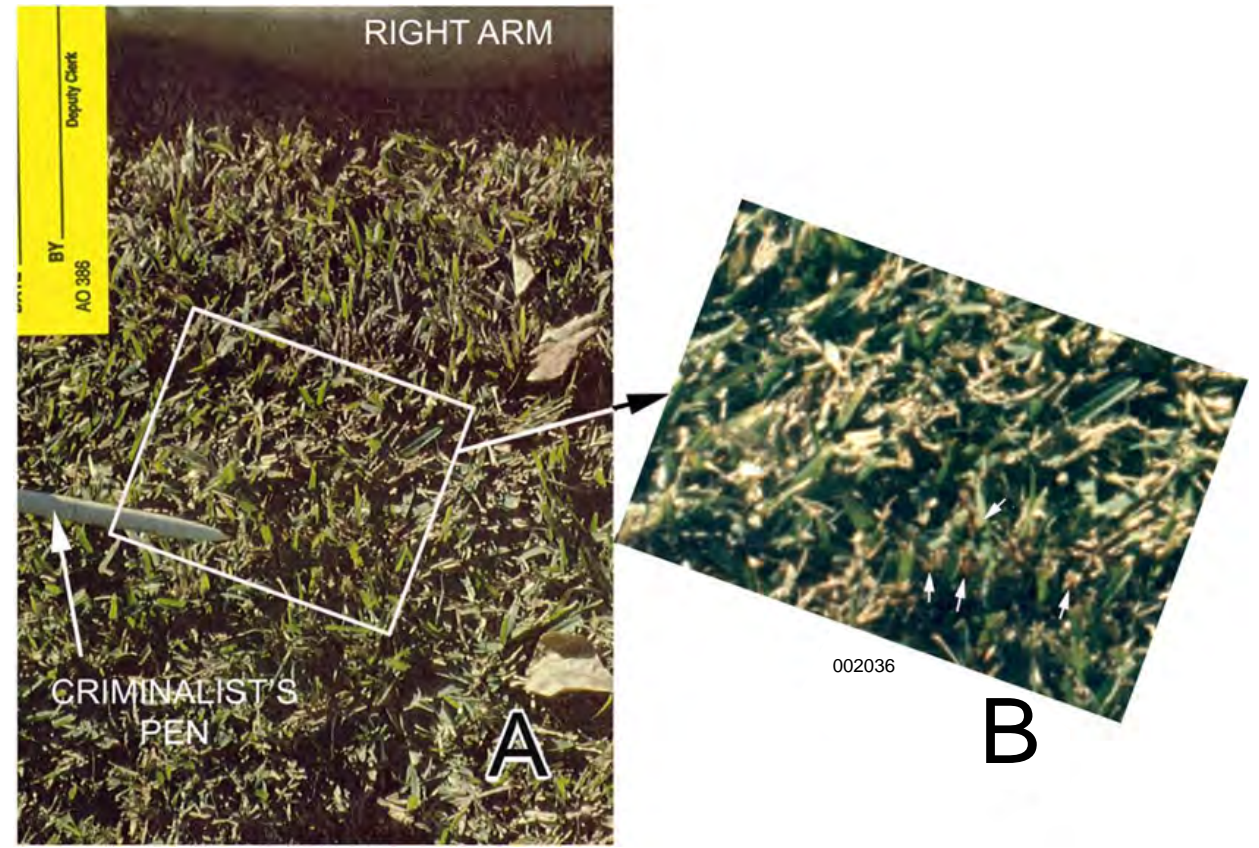

Figure 10: Scene images of the area of grass bloodstain G; images globally enhanced with Photoshop. A:The criminalist's pen can be seen in this photograph of the area of bloodstain G. B: The bloodstain is made up of small droplets of blood (at arrows) that can be seen on the blades of grass. The origin of this blood is expirated which was deposited prior to the intraoral shotgun blast. 
Citation: Burnett BR (2017) The Homicide of United States Marine Corps Colonel, James E. Sabow: A Forensic Analysis Submitted to the United States Congress. J Forensic Res 7: 362. doi: 10.4172/2157-7145.1000362
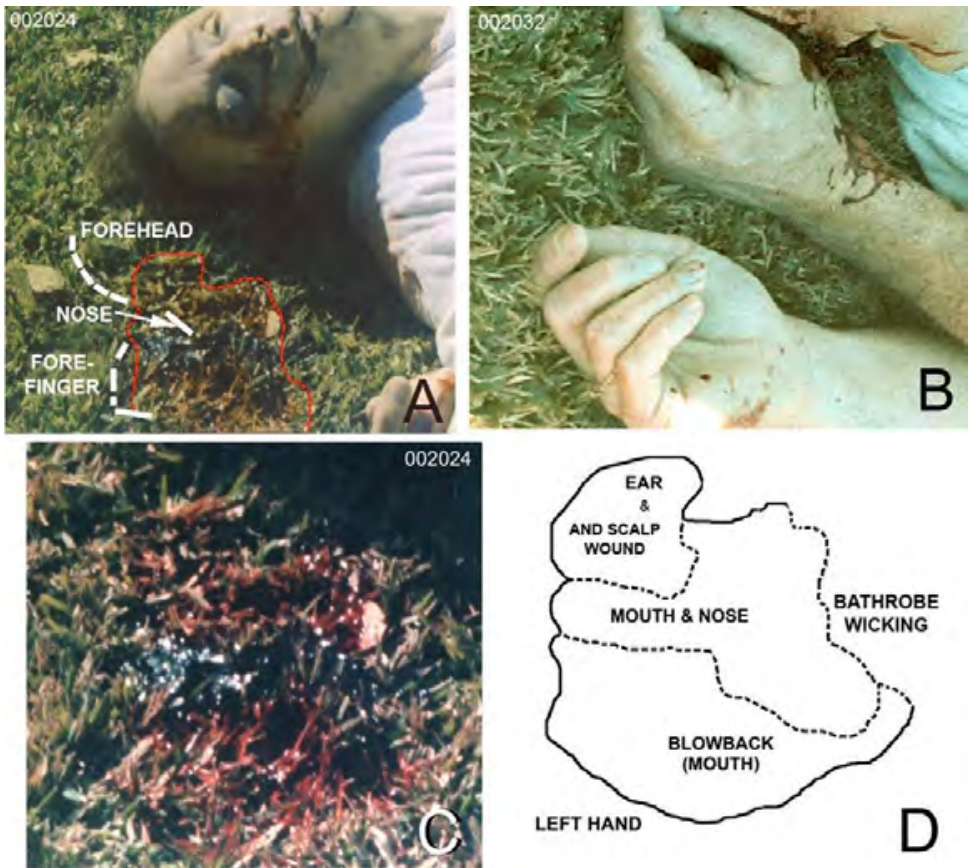

Figure 11: Analysis of the bloodstain in the grass under and in front of the head of the victim. A: The bloodstain showing where the forehead, nose and left hand forefinger were in relation to the bloodstain. The position of the head over the bloodstain was estimated comparing features of the grass and leaves (there was little or no wind during the scene processing) in the photographs before and after the body was turned over. B: The hands of the victim. The left hand blocked the blowback in that no bloodstain is apparent between the left and right hands. C: From the same photograph as A, but enlarge and Photoshop globally enhanced to show the distribution of the types of bloodstains. D: Map of the bloodstain showing the likely origin of the regions of the bloodstain.

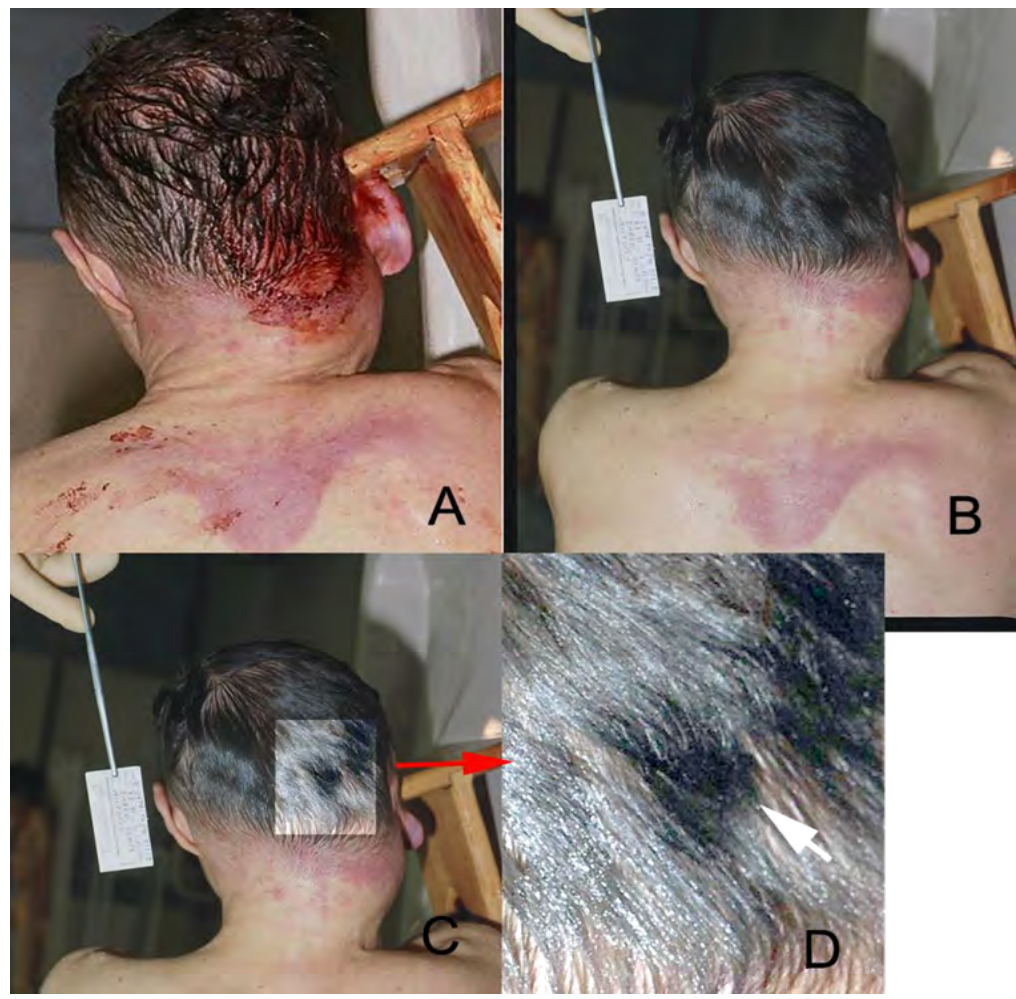

Figure 12: Images of photographs of the posterior of the Colonel from the Orange County Coroner received in 2012. A: Photograph showing a blood ring around the right occipital wound; photograph taken prior to cleaning the body, B: Posterior of the body after the cleaning, C: Same image as B, but the right occipital region lightened using Photoshop, D: The lightened region in C enlarged showing a wound (arrow) overlying the depressed skull fracture. 
Citation: Burnett BR (2017) The Homicide of United States Marine Corps Colonel, James E. Sabow: A Forensic Analysis Submitted to the United States Congress. J Forensic Res 7: 362. doi: 10.4172/2157-7145.1000362

bloodstain on the forefinger (Figure 8A (circle), Figure 13 (circle and inset)) and the palm bloodstain itself. The forefinger was shielded by the thumb and fingers three of projected blood from the mouth and occurred by the left hand being directly in front of the mouth when bloody blowback occurred. In addition, the blood on the lateral portion of the ventral palm is smeared (Figure 13) where the smear is directed proximally from the palm to the distal (ulnar) margin of the wrist. The transfer occurred when the blood on the palm had partially coagulated.

Two bloodstains on the left arm just proximal to the expirated bloodstain (Figure 13, yellow arrows) both have spines and satellite spatter that indicate a proximal directional vector of deposition on the ventral arm (Figure 13, smaller pink arrows). These two bloodstains originated from the mouth either during the bloody expiration period or more likely as part of the bloody blowback.

\section{The right hand}

Images of the victim's right hand from three different scene photographs are shown in Figure 14. These photographs show two types of bloodstains: blood spatter and transferred blood. The right palm and the nail of finger four show small blood spatters (Figures 14A and 14B arrows). Because of the small size and location of these bloodstains, they were generated either during the period of blood expiration or by bloody blowback.

The ulnar aspect of the right palm, extending around to the back of the hand, is a blood transfer (Figures 14A, 14B and in its entirety in Figure 14C). The size and shape of this bloodstain indicate it is likely a transfer from the left palm that occurred after the blowback blood went into the palm and dorsal fingers of the left hand.

If the right hand depressed the trigger in the suicide scenario, its palm would be turned away from the mouth (Figures 2A, 5A, 5B and $5 \mathrm{C}$ ), and not be exposed to intercept blood spatter.

\section{The face and bathrobe}

There are a number of bloodstains on the face of the Colonel, most of which are around the nose and the mouth (Figure 15A and 15B). These bloodstains likely were deposited by reflected blowbacks which were subsequently smeared when the Colonel's wife held his head on her lap after she discovered his body [28]. Her dress was bloodied [27]. Two blood drops on the chin of the Colonel (Figure 15B, arrows) had flowed toward the mouth. The origins of these blood flows are indicated by arrows. This is consistent with the found position of the body and not consistent in the suicide scenario, where these blood drops should have flowed in the opposite direction, while the victim was sitting (Figure $2 \mathrm{~A}$ ) and then changed flow direction to correspond to the final position of the body (Figure 1). A small blood drop hit the anterior left pinna (Figure 15C) and flowed anteriorly in concordance with the position of the body, also without a change in direction.

There are small bloodstains on the chest area of the bathrobe

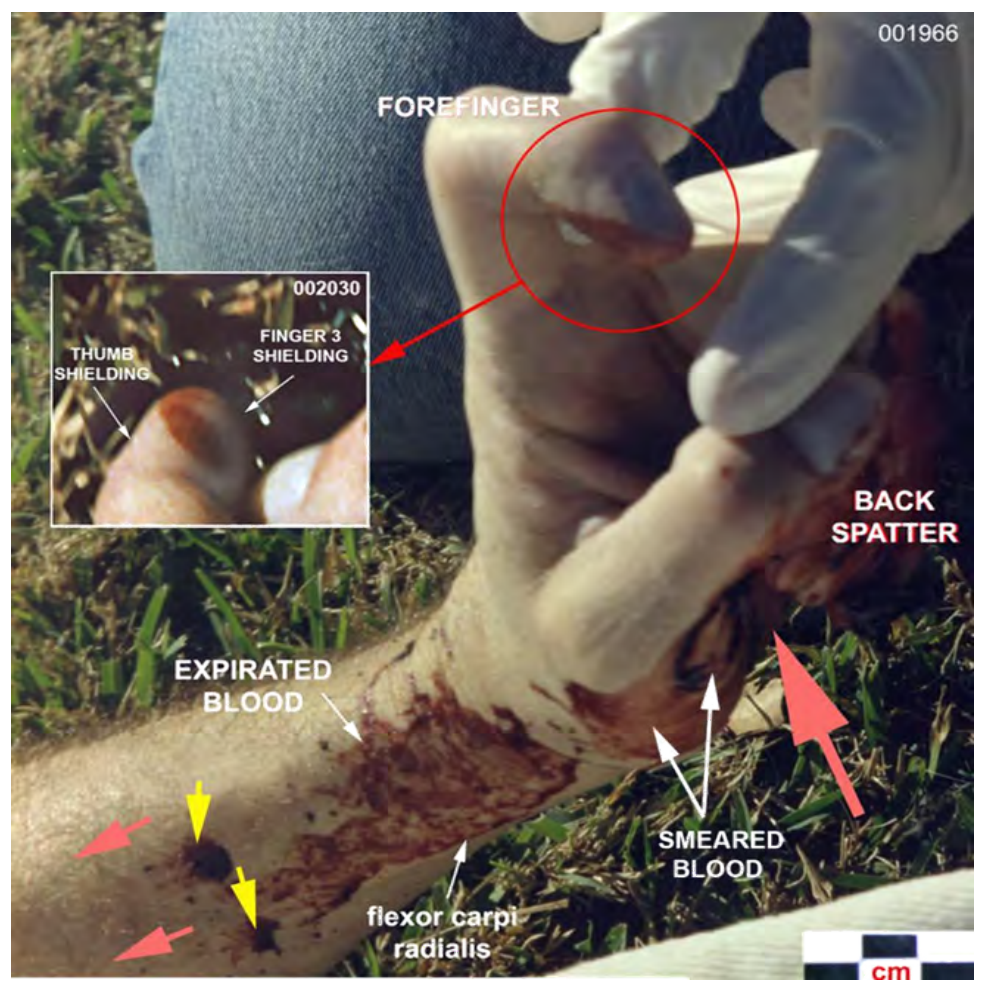

Figure 13: The bloodstains of the left hand and arm; the large pink arrow indicates the direction from which the bloodstain was deposited in blowback. The blood droplets at the yellow arrows originated either from expirated blood or projected blood from blowback. Circle: the forefinger tip was shielded by the thumb. Inset: The forefinger in a more ventral view revealing a shielding by finger three had occurred. These images show that the blood on the palm and dorsal distal fingers originated while directly in front of the mouth, i.e., from the bloody blowback event. Bloody blowback was directed into the palm as indicated by the large pink arrow. The smaller pink arrows show the direction of deposition (toward the proximate arm) for these bloodstains and were likely a part of the bloody blowback. The large bloodstain on the wrist has voids (originally bubbles) and an apparent mucus involvement can be seen throughout the bloodstain. This is a typical expirated bloodstain. Bloodstain smear -SMEARED BLOOD was caused by the victim's right ulnar palm likely due to postmortem manipulation of the body. The circular dark bloodstain (left of the large pink arrow) is the dried margin of a portion of the blowback bloodstain that was subject to smearing. Scale at the lower right corner of the image was made at the wrist and was derived from a simulation scaling. 
Citation: Burnett BR (2017) The Homicide of United States Marine Corps Colonel, James E. Sabow: A Forensic Analysis Submitted to the United States Congress. J Forensic Res 7: 362. doi: 10.4172/2157-7145.1000362

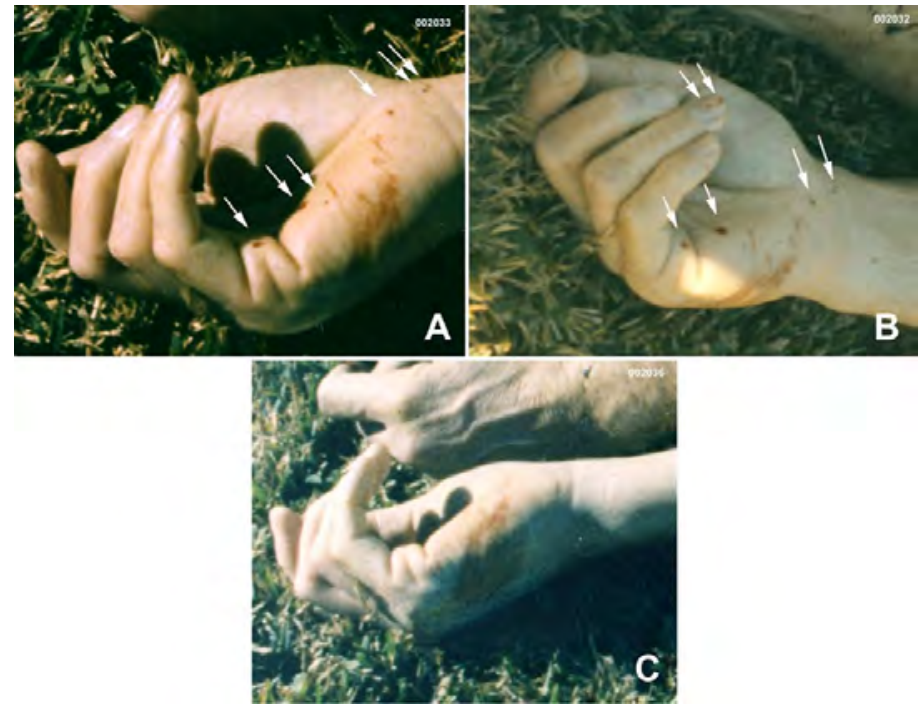

Figure 14: The right hand of the victim from death scene photographs; all of the images are enhanced. A: The two types of bloodstains are shown. The white arrows point to blood spatter. B: The white arrows point to projected spatter; blood spatter on the nail of the fourth finger is clearly visible. C: The entire transfer bloodstain on the back of the hand is shown (image enhanced by Photoshop).

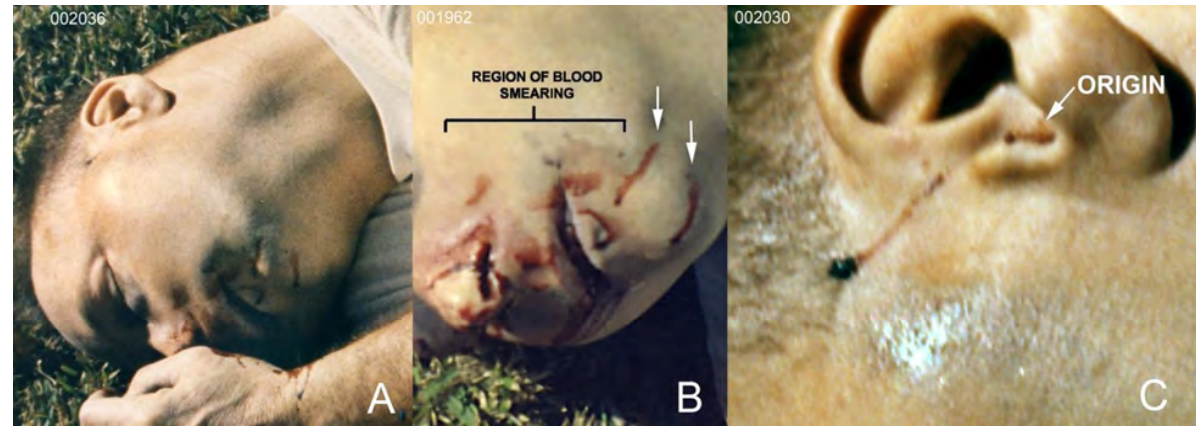

Figure 15: A: Blood spatter on the left side of the face likely originated from deflected blowback blood off the left palm and dorsal distal fingers. This is additional evidence that places the left hand in front of the mouth at blowback. Such deposition could not happen in the suicide scenario. B: Blood smearing and two spatter drops on the chin (origins at arrows). The flow of blood from the chin toward the mouth is consistent with the victim's head as originally found and with the shotgun blast delivered when the victim was on the ground. C: Enlargement of a scene photograph showing the reflected bloody blowback on the anterior left pinna of the victim which flowed toward the top of the head. This is again consistent with the victim's head as found and with the intraoral shogun discharge occurring while the Colonel was on the ground (Figure 2B).

(Figure 16A) and a blood spatter on the left sleeve (Figure 16B) as well as one other in the right arm which was mentioned in the video, but not recorded by a photograph available to this study.

\section{The bathrobe - wicked bloodstain}

The bathrobe that was in contact with the large bloodstain in front of the face, absorbed blood serum in a wicking manner (Figure 16C).

\section{Discussion of the Blood Evidence}

\section{Ear bleeding and expirated blood}

The blow to the head not only caused the depressed fracture of the right occipital but a severe basilar skull fracture [6]. It was the basilar skull fracture that lacerated the mucosa of the nasopharynx [1] and was the major blood source in the aspiration and expiration of blood. Blood from a basilar skull fracture often invades the middle ear and if severe enough, there is bleeding from the ear canal [29], as happened in this case.

\section{Bloodstains $\mathrm{G}$ and $\mathrm{H}$}

Bloodstains $\mathrm{G}$ and $\mathrm{H}$ are consistent with the homicide scenario where the Colonel was first struck with a club and fell to the ground lying on his right side. In extremis, he exhibited brainstem seizures (decerebrate and decorticate postures [30]) and hyperventilation during which time he forcefully expirated and inhaled blood into the right lung [31] resulting in the right lung accumulating a large amount of blood [1]. The grass bloodstains labeled $\mathrm{G}$ and $\mathrm{H}$ are small blood droplets on the grass blades of the grass (Figure 10B) that resulted from the expiration of blood. These bloodstains also indicate the Colonel's body/head had repositioned at least twice prior to the final body position shown in the scene images. For the suicide scenario, $\mathrm{G}$ and $\mathrm{H}$ would have had to result from blowback because expiration would be 
Citation: Burnett BR (2017) The Homicide of United States Marine Corps Colonel, James E. Sabow: A Forensic Analysis Submitted to the United States Congress. J Forensic Res 7: 362. doi: 10.4172/2157-7145.1000362

Page 16 of 20

impossible without a brainstem [1,30]. In the suicide scenario (Figure 2A), the Colonel would be sitting at least four feet distant from these bloodstains. These bloodstains would have been more massive (and readily observed in the scene photographs) if they were the result of projection by blowback in the suicide scenario.

\section{Bloodstains and spatter - Conclusions}

The left wrist shows expirated blood (Figure 13) which is consistent with the victim being initially incapacitated by a severe blow to the back of his head. Blood was expirated through the nose and mouth and deposited on the left wrist while the victim was in a decorticate posture, with his hands near his mouth. The palm and the dorsal distal fingers of the left hand are blood stained with a coating of blood (Figure 13). This is the result of the left hand being within centimetres of the mouth to intercept much of the blowback effluent following the intraoral shotgun blast. The left index finger, however, has a patterned bloodstain, where both the thumb and finger three shielded this finger (Figure 13). These blood patterns and the soot (Figure 8) on the left hand indicate the position and a close proximity of the left palm and fingers to the mouth at the time of bloody blowback.

The radial part of the proximal left palm (Figure 13) is a smear that starts at the base of the palm and goes toward the wrist. The size of the smear and its location indicate the transfer bloodstain on the right hand is from the smeared area on the left hand's palm. Reflected bloody blowback hit the face in a number of places (Figure 15). Most of these blood spatters were likely smeared when the Colonel's wife clutched his head after she discovered his body [28]. Two of these blood spatters remained unsmeared and flowed toward the mouth (Figure 15B) reflective of the head position when the spatter hit.

When the area of soot deposition on the left hand (Figure 8) is included in the homicide scenario, it indicates an assailant placed the victim's left hand over the barrel as shown in the simulation (Figure 2B) before firing the shotgun. The stock of the shotgun was unsupported and when it was discharged, the recoil tore the muzzle out of the mouth. The left hand dropped to the grass while rotating 90 degrees counter clockwise so that the palm was juxtaposed to the mouth by the time of the bloody blowback. This supports the observation of a short delay from a contact or near contact gunshot into a skull to the bloody blowback event [8].

The right hand was likely within centimetres of the mouth, behind the left hand (Figure 1A and $1 \mathrm{~B}$ ), at the time of receipt of its blood spatter. Regardless of the source of the blood, either from expiration or the bloody blowback event, the right hand was shielded by the victim's left hand. This spatter could have occurred only in the homicide scenario, since in the suicide scenario the right hand would be at the trigger of the shotgun (Figure 2A), a position where blood deposition such as seen on the right hand could not have occurred.

After blowback, passive bleeding from the mouth and nose continued for a short time creating the majority of the bloodstain in the grass beneath and in front of the victim's head (Figure 11A, 11C and 11D). The position of this bloodstain in relation to the head indicates that bleeding from the mouth and nose was more substantial than from the right ear. In addition, part of the bloodstain in the grass is from the blowback event itself (Figure 11C and 11D). The accumulation of blood contacted the right shoulder of the bathrobe, where there was serum wicking (Figure 16C).

\section{Staging the body}

The assailants, during the staging of the Colonel's body, likely slightly moved his arms and hands. There was a postmortem modification of the scene in regards to forefinger and thumb of the left hand and the position of the right hand (Figure 17). During the adjusting the bathrobe and pajama bottom to the positions (Figure 1), the upper part of the body was lifted perhaps bringing the right hand under and into the palm of the left hand at this time. However, the Colonel's wife also manipulated the body [28] which could have caused this. Either way, the right and left hands attained positions different than their premanipulation positions.

\section{The body position, clothing and the shotgun}

The blow to the back of the Colonel's head is documented [6]. The brainstem was severely injured by the blow. Such injuries have a high probability of causing decerebrate and decorticate posturing [30]. Lip and tongue biting, which occur with decerebrate and decorticate posturing [30], were documented for the Colonel [6]. The expirated bloodstains $\mathrm{G}$ and $\mathrm{H}$ in the grass (Figures 3 and 10) occurred when the Colonel was shifting between decerebrate and decorticate posturings. The expirated bloodstains were deposited at different positions in the grass (bloodstains $\mathrm{G}$ and $\mathrm{H}$ ) and the left ventral arm as the Colonel transitioned between seizures. The body of the Colonel (Figure 1) was found in a decorticate posture, the position when death occurred.

\section{The bathrobe}

The initial perception by an inexperienced person of the Colonel's bathrobe's position and configuration when the scene photographs
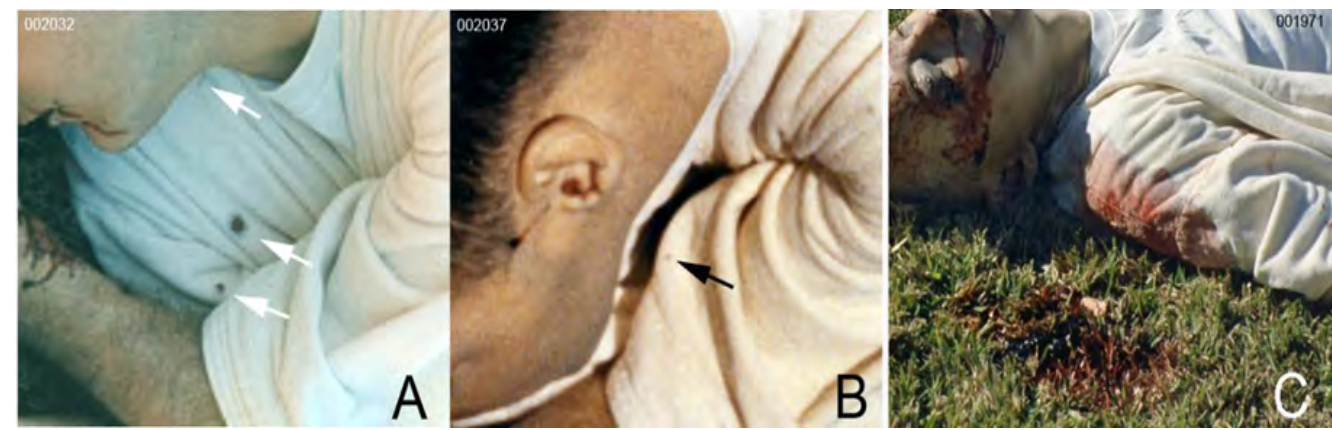

Figure 16: A and B: Blood spatter on the bathrobe at arrows that likely occurred as splash-back on the left hand from the blowback event. C: The bloodstain on the bathrobe shoulder. There was little, if any, direct blood deposition from the source (the mouth and nose). The bloodstain appears to be mostly serum that was wicked from the large bloodstain under and in front of the victim's head. 
are first examined is that it adheres to a suicide scenario. That is, the Colonel was sitting in that patio chair, inserted the shotgun in his mouth placed his left hand around the barrel at his mouth, and with his right hand depressed the trigger (Figure 2A). It is unusual he would tuck the bathrobe between his legs to his crotch (Figure 18) prior to the shotgun discharge, but this feature did not initially contribute to the suspicion of body staging. However, several other scene images with the patio chair on top of the Colonel revealed an extraordinary feature of the bathrobe: it was also tucked between the legs at the buttock (Figure 19).

The anterior of the body shows the tuck in the bathrobe from the knees to the crotch (Figure 18, arrow). The posterior of the body (Figure 19A), the bathrobe has the initial appearance of having been snagged by the patio chair when the victim fell backward as alleged to have occurred in the suicide scenario. However, enhancement of this image (Figure 19B) reveals the folds in the bathrobe converge toward the proximal legs at the buttocks. Another image (Figure 19C) shows the bathrobe tightly applied to the buttock and upper left leg through the webbing of the patio chair (Figure 19D). A simulation of the bathrobe on a mannequin (Figure 19E) shows in order to have the configuration of the folds as shown on the victim (Figures 19A and 19B), the bathrobe must have been tucked between the legs at the buttocks.

It is impossible for the Colonel to have tucked in his bathrobe both front and back prior to the alleged suicide in a patio chair. These features must have been performed by somebody else. The body was staged.

It is unfortunate pictures of the Colonel at the scene were not taken with the patio chair removed. The video recording of the scene processing showed there were no photographs taken of the rear of the body from the removal of the chair to turning the body onto its back. If those pictures had been taken, the staging of the body would have been obvious. Perhaps if Nordby [2,4] had discovered this feature of the body, he would not have concluded the Colonel died by suicide.

\section{The shotgun}

The discovery for this case had scant information concerning the shotgun except for the comment, the muzzle of the shotgun was visually examined which disclosed what appeared to be minute amounts of

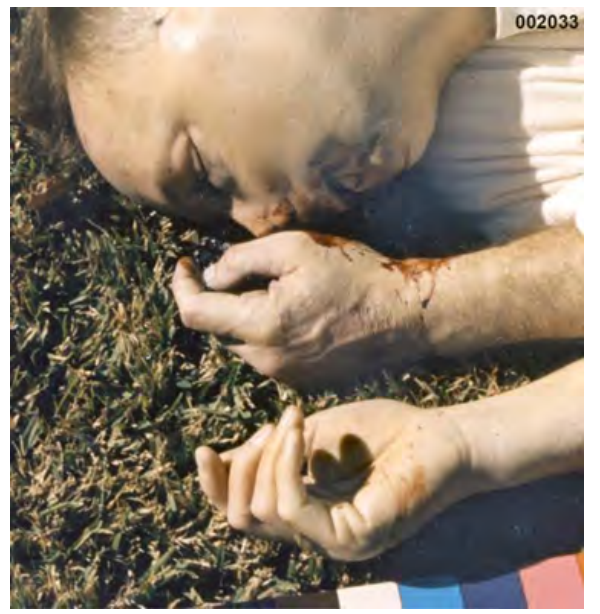

Figure 17: Positions of the hands at the scene. The left hand has nearly the same position that it had at the major blowback event. However, both the thumb and the forefinger became more extended after blowback. The patterned bloodstain on the forefinger is away from the mouth - it could not have received this bloodstain at this position. The left hand shielded the right at the bloody blowback (see text). Manipulation of the arms and head occurred post shotgun discharge/blowback

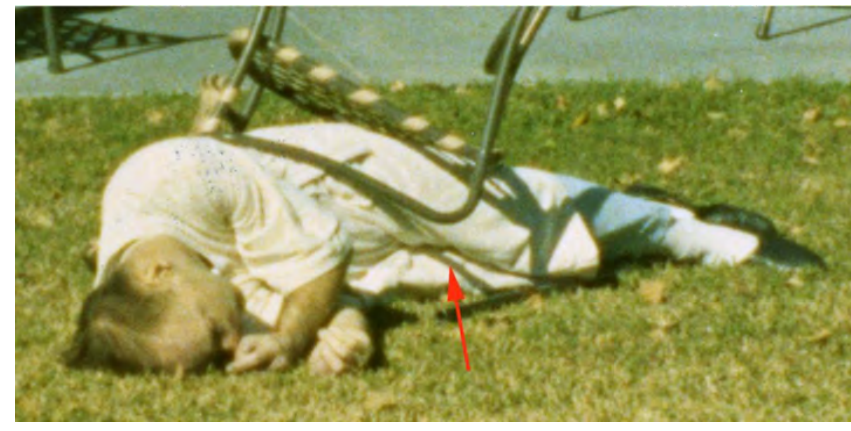

Figure 18: Death scene photograph showing the Colonel's bathrobe tucked between his legs at the crotch (arrow).

tissue blowback within the barrels. No blood deposits or anything else connected to the Colonel's death was noted on the shotgun. In the suicide scenario, bloodying of the shotgun should have occurred. The lack of blood on the shotgun and the lack of fingerprints on the exterior surface of the shotgun [5] indicate the shotgun was cleaned prior to being placed under the Colonel's legs.

\section{Reconstruction of the Homicide}

The Colonel was subdued by three persons. The attackers planned to stage a suicide. In order for this plan to work, they had to be certain that their victim did not show signs of their attack (bruises, abrasions, grass stains on the clothing, etc.). While the victim was being held, likely by a person holding each arm, his head was forced down and a club or board was brought down with considerable force on the right occiput of the Colonel's skull (Figure 20). A depressed cranial fracture on the right occipital skull is evident as well as an abrasion and massive hematoma at the right occipital area of the head [6]. The victim fell to the ground and lay on his right side, severely wounded but still alive. He continued to breathe for at least several minutes and aspirated over one-half litre of blood into his right lung [1]. While in this unconscious state, he exhibited brainstem convulsions (decerebrate and decorticate posturing [30]) during which time he lacerated and bruised his upper and lower lips as well as his anterior tongue [6].

In this condition and near death, the victim had central neurogenic hyperventilation which characteristically occurs with severe brainstem trauma [30] and during which he expirated blood [29] onto his left wrist (Figure 13B) and onto the grass (bloodstains G and H, Figures 3 and 10). Because he continued to live during this period, there was sufficient time elapse for a hematoma to form over the depressed skull fracture [6] as well as swelling on the right side of his head and distal right posterior neck $[6,32]$. From the time of the initial attack until the time he expired, bleeding was occurring from the lacerated lips, the lacerated tongue and the posterior pharynx. This blood was both expirated and inhaled. The shearing force to the brainstem that would have followed a blow to the back of the skull resulting in such a depressed skull fracture, also would have extensively and irreversibly injured the brainstem [30]. In all likelihood the blow caused hemorrhage within the substance of the brainstem, in addition to having caused laceration of the blood vessels supplying the brainstem [6].

While the victim lay on his right side with his upper extremities bent in front of him in a decorticate posture, an assailant jammed the barrel of the Colonel's 12 gauge shotgun into his mouth. The placement of the barrel required a left rotation of the dead victim's head, simply 
Citation: Burnett BR (2017) The Homicide of United States Marine Corps Colonel, James E. Sabow: A Forensic Analysis Submitted to the United States Congress. J Forensic Res 7: 362. doi: 10.4172/2157-7145.1000362

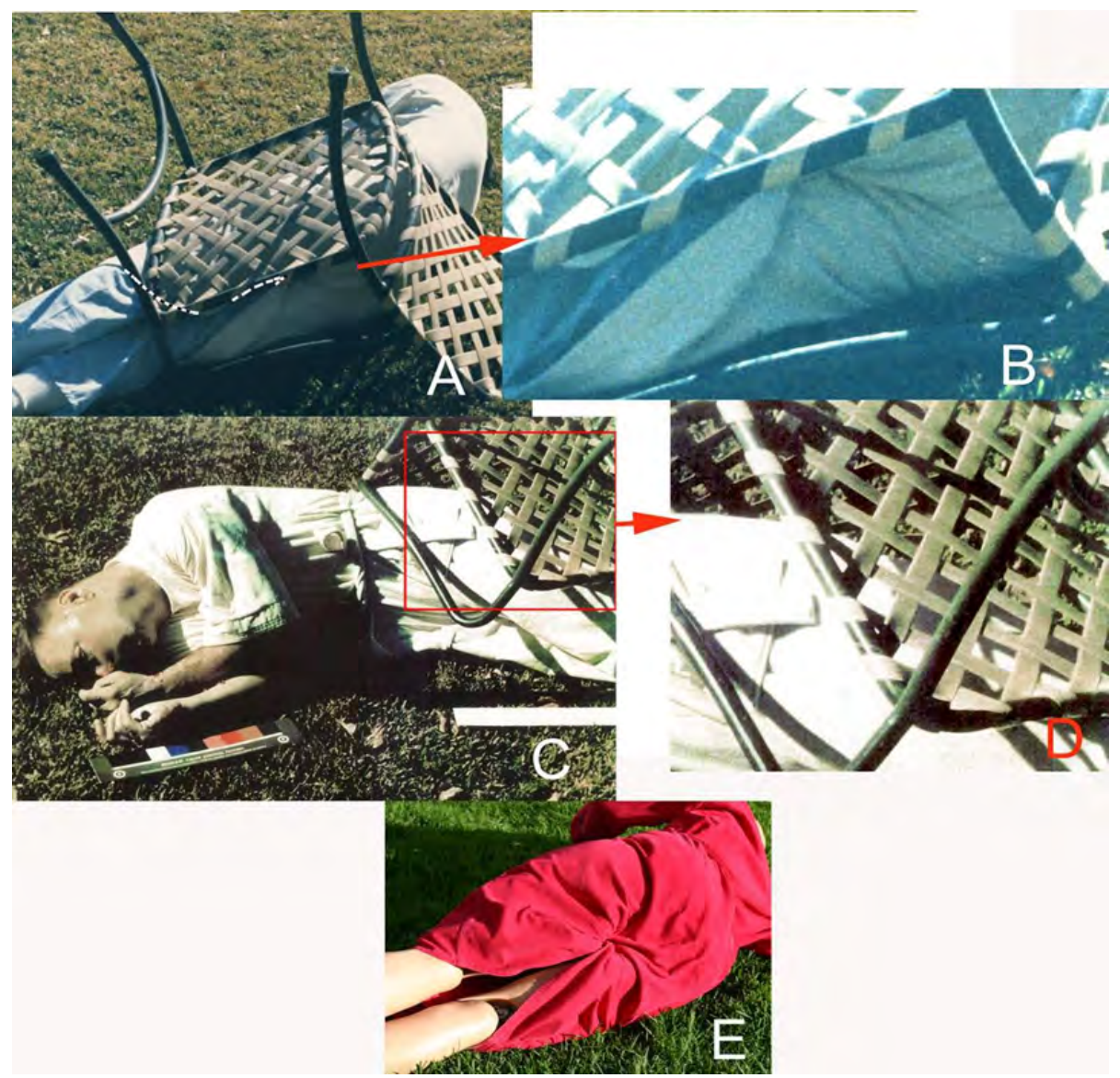

Figure 19: Death scene photographs showing the bathrobe tucked between the Colonel's posterior legs to his buttocks. A: Photograph of the Colonel from the rear; the white dashed lined approximates the lower hem of the bathrobe under the chair seat. B: Enlargement of A (enhanced in Photoshop). The bathrobe folds into the buttocks. C: An anterior view of the Colonel showing the configuration of the bathrobe under the patio chair. D: Enlarge from C; the bathrobe can be seen clinging to the buttock (enhanced in Photoshop. This documents the folding of the bathrobe into the buttocks and not a snagging by the chair of the bathrobe. E: A simulation using a mannequin that approximates the rear folding of the bathrobe into the buttock of the victim. No photographs of the body in the found position with the chair removed were available. The video of the scene processing showed none were taken.

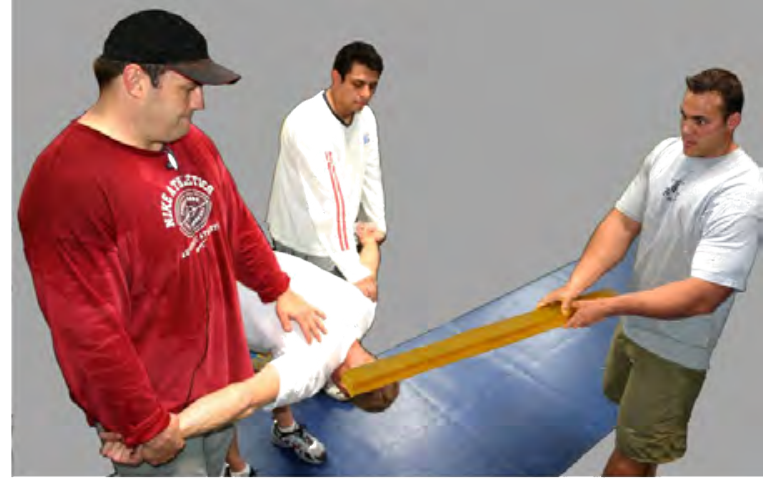

Figure 20: Simulation of the devastating blow to the back of the Colonel's head by a club or board. In this simulation, a $2 \times 4$ inch board is shown. The weapon could have been in a different form (e.g., a hockey stick).

because of his position on the ground with the arms and hands situated in front of his face (Figure 17). The left barrel was fired with the muzzle in contact with the soft palate. Because the line of fire was directed through the soft palate, the bony architecture of the skull base absorbed a significant amount of the explosive energy and prevented an exit wound, although there is a possibility that the cartridge powder was reduced to assure no exit wound. If there was an exit wound, that would have indicated the location of the shotgun blast, a scene feature the assailants could not hide in the staging of the body. The shotgun blast was also an attempt to obscure the evidence of blunt force trauma to the back of the head and for one examiner $[2,4]$ it worked. In most intraoral shotgun wounds, the line of fire is directed upward to the thin hard palate and the top of the head is usually blown out [24]. The preference for hard palate placement is due to the gag reflex that originates in the soft palate which prevents intimate placement of threatening objects [29]. The volume of blood resulting from the shotgun blast which otherwise would have been heavy (blowback and passive bleeding), was relatively scant. The Navy physician at the scene estimated the blood loss at $50 \mathrm{cc}$ [33]. The low blood loss was due to the victim's death prior to the shotgun blast where blood circulation had stopped.

The shotgun was discharged into the Colonel's mouth without bracing. This resulted in the rapid muzzle withdraw in recoil from the Colonel's mouth. The left hand received soot through the sides of the mouth while the barrel of the shotgun was still in the victim's mouth. 
Some organic debris was deposited in the barrels of the shotgun [5]. There was a two-phase blowback. The initial blowback involved primarily soot and GSR which deposited on the medial aspects of the forefinger and thumb (Figure 8). After the rapid removal of the shotgun muzzle from the Colonel's mouth, the unsupported left hand rotated counter clockwise 90 degrees while dropping to the grass to a position in front of the mouth and the Colonel's head fell back to its original position where the second phase blowback, mostly bloody blowback, occurred. The bloody blowback hit the left palm, dorsal distal fingers (Figure 13A) and the grass in front of the left hand (Figure 11E).

The blowback blood into the Colonel's left hand and the grass in front of his mouth exited from the entrance wound, the mouth. It has been shown that the mouth was in front of the palms of both hands, with the left hand shielding the right (Figure 17). The left forearm intercepted expirated blood from the nose and the left palm intercepted blowback blood (Figure 13). The bathrobe and pajama were at 90 degrees from the trajectory of blowback and thus both were devoid of direct blowback effluent, although the bathrobe as well as the face received some reflected blowback blood (Figures 14 and 15) from the left palm and fingers.

The GSR evidence shows that the shotgun leaks GSR from the trigger housing and breech. There were no GSR focal concentrations that would occur with the breech in close proximity to the bathrobe or pajama bottom in the suicide scenario. Indeed, the bathrobe did not have significant GSR association, except possibly on its lower hem [4], despite being the article of clothing that would be exposed to GSR contamination (Figure 1) regardless of the death scenario. The shotgun breech was away from the bathrobe and pajama bottom as the homicide scenario (Figure 2B) would predict. In addition, the pajama bottom of the victim, although mostly covered by the bathrobe when the body was found, had significant levels of GSR associated in areas that were under the bathrobe cover. The pajama buttocks were GSR contaminated which could be due to either the GSR-laden cloud from the shotgun's breech leakage, early blowback and the shotgun muzzle after its removal from the mouth in recoil which drifted over the lower half of the victim. Or the shooter, who was contaminated with GSR, participated in staging of the body. It is apparent the bathrobe was partially folded over itself and hiked up on the body when the shotgun discharged. The front upper chest of the bathrobe was exposed at the time of the shotgun blast because some blood spatter was observed in this area (Figures $15 \mathrm{~A}$ and 15B). The bathrobe of the upper chest was not contaminated with GSR. This suggests during initial soot-laden blowback that the left hand did not deflect GSR to the chest, unlike the blood-laden blowback which hit the left palm and dorsal distal fingers and deflected some blood back onto the bathrobe and face.

The behaviour of the shotgun would be quite different in the suicide scenario in that it would be stationary with the stock on the ground upon discharge into the mouth. The energy of the blast would jerk the head back from the muzzle due to there being no exit wound. At the time of the head jerking back, blowback would occur and contaminate the bathrobe and shotgun with GSR, BSR, blood, bone and other tissue. The left hand would immediately begin its drop from the shotgun barrel and would be in a position at blowback to receive blood and the blocking effect of the shotgun barrel would be apparent in the palm and finger bloodstains on the left hand. In addition, there was no mention in any of the discovery that the shotgun had bloodstains on its surfaces. Within a second or two after the shotgun discharge in the suicide scenario, the Colonel would fall backward and to his right from the chair. The final position of the body (Figure 3) in relationship to the location of the patio chair that the Colonel allegedly sat for the suicide (Figure 2A) also makes the suicide scenario completely untenable. Brainstem destruction, as had to have occurred, causes all muscles to immediately become flaccid [30] and would not allow for the victim essentially jumping into a fully stretched-out position.

After the intraoral shotgun blast, postmortem manipulation of the Colonel's bathrobe took place. The assailants cleaned the exterior of the shotgun and placed it under the decedent's legs in order to appear that he shot himself while sitting in a patio chair, falling backward and to his right and on top of the shotgun. The lawn chair was placed on top of the body to complete the suicide image. The assailants, in an apparent assassin faux pas, tucked the bathrobe between the legs both front and rear. The attempt to hide this homicide by staging of the body to appear to be a suicide show there was an ill-conceived plan for the homicide and postmortem manipulation of the body.

On top of the overwhelming evidence of homicide, one of the autopsy photographs submitted by the Department of Defense in a civil trial in Federal Court as well to the US Congress was fraudulent [3].

\section{Acknowledgements}

Many thanks to Dr. Josef Lebiedzik for his extraordinarily valuable assistance in this project. Permission to use the crime scene and autopsy photographs in this publication by Dr. David Sabow, brother of Colonel James E. Sabow.

\section{References}

1. Singhania A (1991) Autopsy record: Sabow, James Emery. Case Number 9100474-SU, Forensic Science Center, Orange County Sheriff-Coroner, USA.

2. Nordby J (2004) Shotgun death of Col. Sabow. Report under Federal Contract HQ00095-04-C-002. Law Enforcement Policy and Support (Department of Defense), Washington DC, USA.

3. Burnett BR (2016) Analysis of fraudulent photographs submitted to Federal Court and the United States Congress. J Forensic Res 7: 343.

4. Nordby J (2006) Shotgun death of Col. James E. Sabow. Report under Federal Contract HQ00034-05-R-1014. Law Enforcement Policy and Support (Department of Defense), Washington DC, USA.

5. Naval Investigative Service (1991)b V/Sabow, James Emery/Col USMC (Deceased). Examination of victim at death scene and at Coroner's facility.

6. MacLachlan, R (2016) Pathology: Neurology and Cranial Injuries. Chapter 16 In: O'Dowd, R. Treachery: Murder, Cocaine and the Lucifer Directive, O'Dowd Publishing LLC. Somerdale, New Jersey, USA

7. Wolten GM, Nesbitt RR, Calloway AR, Lopez GL, Jones PF (1977) Final report on particle analysis for gunshot residue. Report. Aerospace Corporation, El Segundo, California, USA.

8. Burnett BR (1991) Detection of bone and bone-plus-bullet particles in backspatter from close-range shots to heads. J Forensic Sci 36: 1745-1752.

9. Martinez MV (2000) P-GSR detection on clothing and in automobiles International Assoc MicroAnalysis 1: 2-3.

10. Burnett BR (2005) The gunshot residue evidence of People v. Robert Blake: A case of forensic alchemy. Meixatech, San Deigo USA.

11. Burnett BR (2007) People v. Phil Spector. The missing gunshot residue evidence and misinterpreted blood spatter evidence. The Daily Transcript (San Diego), USA.

12. Mann M, Espinoza EO (1993) The incidence of transient gunshot prime residue in Oregon and Washington bow hunters. J Forensic Sci 38: 23-27.

13. Wright DM, Trimpe MA (2006) Summary of the FBI Laboratory's gunshot residue symposium. Forensic Sci Communications 8: 1-17.

14. Niemeyer WD (2000) Gunshot residue from strange places. International Assoc MicroAnalysis 1: 8-9.

15. Chavez C, Crowe C, Franco $L$ (2001) The retention of gunshot residue on clothing after laundering. International Assoc MicroAnalysis 2: 1-7. 
Citation: Burnett BR (2017) The Homicide of United States Marine Corps Colonel, James E. Sabow: A Forensic Analysis Submitted to the United States Congress. J Forensic Res 7: 362. doi: 10.4172/2157-7145.1000362

Page 20 of 20

16. White RS, Gross ML (1994) Deposition of gunshot residue at various distances from discharging firearms. The Seminar 4: 8-14.

17. Zeichner A, Foner HA, Dvorachek M, Bergman P, Levin N (1989) Concentration techniques for the detection of gunshot residue by scanning electron microscopy/energy dispersive X-ray analysis. J Forensic Sci 34: 312-320.

18. Anonymous (1991) Physical evidence report (V) SABOW James Emery. California Department of Justice, Riverside Regional Criminalistics Laboratory, California, USA.

19. Maritz P (2006) Death Investigation, SD Forensic Lab \#05-346, James Emery Sabow, victim. Office of the Attorney General, DCI Forensic Laboratory, State of South Dakota, USA.

20. Schwoeble AJ, Harrison LG, Foster E, Freebling DM (2006) SEM analysis of gunshot residue samples. DCl Forensic Laboratory, Case Number 05-346. Sabow, James Emery Report, RJLee Group, Inc., USA.

21. Romolo FS, Margot $P$ (2001) Identification of gunshot residue: a critical review. Forensic Sci Int 119: 195-211.

22. Matty W, Miller L (1993) Determination of gunshot residue lost for atomic absorption analysis due to use of adhesive lifts prior to cotton swab sampling. AFTE Journal 25: 13-17.

23. https://wunderground.com/history/airport/KSNA/1991/1/22/

24. DiMaio VJ (1999) Gunshot wounds-Practical aspects of firearms, ballistics and forensic techniques. ( $2^{\text {nd }}$ Edn), CRC Press, New York, USA.
25. Cao X, Ma LQ, Singh SP, Chen M, Harris GW, et al. (2003) Field demonstration of metal immobilization contaminated soils using phosphate amendments. Final Report, Florida Institute of Phosphate Research. Florida Industrial and Phosphate Research Institute, Florida, USA.

26. Burnett BR (2005) Investigation of the death of Colonel Sabow: Gunshot residue, back spatter and death scene analysis. (preliminary) report to Congressman Duncan Hunter, Chairman of the Armed Services Committee, Congress of the United States, USA.

27. James SH, Kish PE, Sutton TP (2005) Principles of bloodstain pattern analysis. Theory and practice. Taylor and Francis, New York, USA.

28. Sabow S (1991) Summary of the interview of Sally Sabow. Naval Investigative Service, USA.

29. Wyngaarden J, Smith L (1985) Cecil Textbook of Medicine, W.B. Saunders Company.

30. Posner JB, Saper CB, Schiff N, Plum F (2007) Plum and Posner's diagnosis of stupor and coma. Oxford University Press, New York, USA.

31. Feldman JL (1994) Comments concerning the death of Col. James Sabow.

32. Remley KB (1996) Neurosurgery-neuroradiology combined conference concerning James Sabow. University of Minnesota, Medical School, Department of Radiology, USA. Neuroradiology Section. Minnesota, USA.

33. Gibbs S (1991) MCAS EI Torro EMS Report (Emergency Medical Service). 